OPEN ACCESS

Edited by:

Remo Castro Russo,

Federal University of Minas Gerais,

Brazil

Reviewed by: Silvia Martina Ferrari,

University of Pisa, Italy

Alessandro Antonelli,

University of Pisa, Italy

*Correspondence:

Aizhong Liu

lazroy@live.cn

Specialty section: This article was submitted to Cytokines and Soluble Mediators in Immunity, a section of the journal

Frontiers in Immunology

Received: 28 October 2020

Accepted: 09 March 2021

Published: 13 May 2021

Citation:

Pan X, Kaminga AC, Wen SW and

Liu A (2021) Chemokines in

Prediabetes and Type 2

Diabetes: A Meta-Analysis.

Front. Immunol. 12:622438. doi: 10.3389/fimmu.2021.622438

\section{Chemokines in Prediabetes and Type 2 Diabetes: A Meta-Analysis}

\author{
Xiongfeng Pan ${ }^{1,2}$, Atipatsa C. Kaminga ${ }^{1,3}$, Shi Wu Wen ${ }^{4,5}$ and Aizhong Liu ${ }^{1 *}$ \\ ${ }^{1}$ Department of Epidemiology and Health Statistics, Xiangya School of Public Health, Central South University, Changsha, \\ China, ${ }^{2}$ Hunan Provincial Key Laboratory of Clinical Epidemiology, Xiangya School of Public Health, Central South University, \\ Changsha, China, ${ }^{3}$ Department of Mathematics and Statistics, Mzuzu University, Mzuzu, Malawi, ${ }^{4}$ OMNI Research Group, \\ Ottawa Hospital Research Institute, Ottawa, ON, Canada, ${ }^{5}$ Department of Obstetrics and Gynaecology and School of \\ Epidemiology and Public Health, University of Ottawa Faculty of Medicine, Ottawa, ON, Canada
}

Background: A growing number of studies found inconsistent results on the role of chemokines in the progression of type 2 diabetes (T2DM) and prediabetes (PDM). The purpose of this meta-analysis was to summarize the results of previous studies on the association between the chemokines system and T2DM/PDM.

Methods: We searched in the databases, PubMed, Web of Science, Embase and Cochrane Library, for eligible studies published not later than March 1, 2020. Data extraction was performed independently by 2 reviewers, on a standardized, prepiloted form. Group differences in chemokines concentrations were summarized using the standardized mean difference (SMD) with a 95\% confidence interval (CI), calculated by performing a meta-analysis using the random-effects model.

Results: We identified 98 relevant studies that investigated the association between 32 different chemokines and T2DM/PDM. Altogether, these studies involved 14,708 patients and 14,574 controls. Results showed that the concentrations of CCL1, CCL2, CCL4, CCL5, CCL11, CXCL8, CXCL10 and CX3CL1 in the T2DM patients were significantly higher than that in the controls, while no difference in these concentrations was found between the PDM patients and controls.

Conclusion: Progression of T2DM may be associated with elevated concentrations of chemokines.

Meta-Analysis Registration: PROSPERO, identifier CRD42019148305.

Keywords: chemokines, type 2 diabetes, prediabetes, inflammation, meta-analysis

\section{BACKGROUND}

With the growing global prevalence of obesity, the incidence of type 2 diabetes (T2DM) continues to increase and this has become one of the most important public health problems worldwide (1). T2DM cannot be completely cured, which seriously affects the quality of life of patients (2). Currently, research has shown that targeted anti-inflammatory drugs have great potential in improving insulin sensitivity and B-cell function (3). Meanwhile, a newly published metaanalysis showed that T2DM risk was closely related to the increased levels of inflammatory 
cytokines such as Tumor necrosis factor- $\alpha$ (TNF- $\alpha$ ), Interleukin-1 beta (IL-1 $\beta$ ), Interleukin-6 (IL-6), Interleukin-18 (IL-18), and C-reactive protein (CRP) (4). Also, accumulating evidence support an important hypothesis that there may be a complex interaction between chronic inflammation and the progression of diabetes $(5,6)$.

Furthermore, studies have shown that in addition to these inflammatory markers, chemokines have become key signaling molecules regulating the pathophysiological process of T2DM (7). Chemokines are the largest family of cytokines composed of four subfamilies (C, CC, CXC, and CX3C) (8). Thus, chemokines have been shown to function as signaling molecules in the inflammatory response, which can activate various proinflammatory mediators and induce various inflammatory factors $(8,9)$. These inflammatory factors stimulate the activation of cytokine signaling proteins, which eventually block the activation of insulin signaling receptors in pancreatic cells, and further induce insulin resistance (IR); hence participate in the progression of prediabetes (PDM) and T2DM (10).

The names of chemokines are not uniform at present. For example, there are about 50 chemokines acting on 23 discrete receptors, and studies on different chemokines in PDM and T2DM patients often produce inconsistent results $(11,12)$. It is unclear which chemokines vary in concentrations in PDM and T2DM patients to be considered as potential new biomarkers.

So far, there has not been a systematic review/meta-analysis on the role of chemokines in the progression of PDM and T2DM. Noteworthy, it is difficult to obtain statistically stable results from a single study. Thus, meta-analysis provides a gold standard method for aggregating data from several similar studies, and helps to improve statistical precision to achieve stable results. Therefore, the purpose of this study was to compare the chemokines concentrations between patients with PDM or T2DM and the control group by means of a metaanalysis, using as many variants of historical and current chemokines as possible retrieved through a wide range of search terms. The illustration of signal transduction pathway of chemokines in the pathophysiological process of PDM and T2DM could provide new targets and strategies for the prevention, diagnosis, and treatment of PDM and T2DM.

\section{METHODS}

\section{Search Strategy and Selection Criteria}

The protocol of this systematic review has been registered in PROSPERO database (https://www.crd.york.ac.uk/PROSPERO), CRD42019148305. Also, the study followed the Preferred Reporting Items for Systematic Reviews and Meta-Analyses (PRISMA) guidelines and the Cochrane Handbook (13).

Due to the inconsistent naming format of chemokines in published articles, the search strategy involved as many variant nomenclatures of chemokines as possible. According to the purpose of this study, two independent reviewers (AL and AK) selected relevant articles. In this regard, the electronic databases of Embase, Web of Science, Cochrane Library, and PubMed were searched for relevant articles published not later than March 1, 2020. The complete search strategy is shown in Appendix 1. Truncation, wildcards and boolean operators were used to allow for the retrieval of as many variant nomenclatures of chemokines as possible. Experienced librarians designed the search algorithm and customized it to meet the search requirements of each of the preceding electronic databases.

The following were inclusion criteria for eligible studies (1): the study design was longitudinal, cross-sectional or casecontrol; (2) the study reported the method for diagnosing PDM or T2DM; and (3) the study reported a mean chemokine concentration and its standard deviation (SD), or these could be obtained from the corresponding author. The exclusion criteria were: (1) letters, reviews, case reports, comments and nonhuman studies; (2) studies reported PDM or T2DM in combination with other diseases; (3) PDM and T2DM patients had the chemokines pharmacologically challenged before their measurements.

\section{Data Extraction}

Two independent reviewers (SW and $\mathrm{AK}$ ) removed the duplicates using EndNote (version X9.1) and entered the eligible studies into a database constructed by EpiData (version 3.0) $(14,15)$. In this database, customized data extraction Excel spreadsheets were used to extract the data for this study (16). Differences between the two independent reviewers were resolved by involving a third reviewer (AL). Therefore, the following data were extracted from the eligible studies:(1) the first author's last name and year of publication; (2) the country where the research was conducted; (3) type of control group; (4) PDM and T2DM patients characteristics such as duration of diabetes (years), waist circumference, waist to hip ratio, systolic blood pressure (SBP), diastolic blood pressure (DBP), fasting plasma glucose/fasting blood glucose (FPG), 2h postprandial blood glucose, Body Mass Index (BMI), age and gender of patients; (5) chemokine sample detection method and storage temperature; (6) sample material of chemokine, mean and standard deviation of chemokine concentration, blood biochemical indexes and other sample characteristics. Finally, the Newcastle-Ottawa Quality Assessment Scale (NOS) was used to assess the risk of bias and quality of eligible studies (17).

\section{Statistical Analysis}

All statistical analyses were performed using the package meta in R (version 3.5.0) (18). Noteworthy, different chemokine assessment methods were used for different studies. Therefore, to be conservative, the random-effects model was used to determine the standardized mean difference (SMD) and 95\% confidence interval (CI) for continuous data (19). Using the restricted maximum-likelihood estimator, the SMD was calculated using the Cohen's d method to synthesize the effect size across studies $(20,21)$. Furthermore, heterogeneity among studies was assessed by the Cochran's Q-test and quantified by the $I^{2}$ statistic $(22,23)$. Thus, $I^{2}=100 \%$ indicated maximal heterogeneity and $I^{2}=0 \%$ indicated no heterogeneity (23). The preceding analysis was first applied on all chemokines concentrations, then on each specific type of chemokine. 
Moreover, subgroup analysis was conducted to explore whether gender (Male and Female subgroups), age ( $\leq 60$ and $>60$ subgroups), and method for measuring chemokines (Luminex method and ELISA method subgroups) had any influence on the results. Sensitivity analysis was carried out using the leave-oneout method. When the number of studies reporting the main results was 10 or more, publication bias was assessed using the funnel plot and Egger's test (24). The significance level was defined as $\mathrm{p}<0.05$ in all analyses, and all tests were two-sided.

\section{RESULTS}

\section{Literature Search}

The search strategy retrieved a total of 8,775 studies, of which 2,720 were from PubMed, 3,780 from Embase, 1,386 from Web of Science, and 889 from Cochrane Library. Thus, 7,922 articles were excluded for being unrelated to this study. Then the full texts of the 853 articles were assessed, and it was found that 755 articles were not eligible for this study, hence they were excluded. Finally, 98 articles were included in the meta-analysis. Appendix 1 shows a flow diagram presenting the selection process of the included studies.

\section{Characteristics of Eligible Studies}

Characteristics of the included studies are shown in Table $\mathbf{1}$ and Appendix 2. Moreover, Appendix 3 shows a systematic summary of the classification of chemokines and the distribution of the cell type of chemokine receptors such as neutrophils, monocytes, mast cells, basophils, dendric cells, CD8 $\mathrm{T}$ cells, and natural killer (NK) cells, in the immune microenvironment. As regards T2DM, the eligible articles included 19 different CC chemokines comparisons involving 7,558 patients and 6,140 controls (Figure 1 and Appendix 4 show forest plots for these chemokines). Also, the eligible articles included a comparison of 13 different CXC chemokines involving 4,145 patients and 4,893 controls (Figure 1 and Appendix 5 show forest plots for these chemokines). For PDM, the eligible articles included 7 different chemokines comparisons involving 3,005 patients and 3,541 controls (Figure 2 and Appendix 6 show forest plots for these chemokines).

Considering sample types of chemokines, 62 eligible studies measured chemokines from peripheral blood samples, 13 from serum samples, 10 from plasma samples, and 13 from other samples. Additionally, the included studies were conducted in China (23), India (9), Italy (6), Japan (6), Germany (5), Iran (5), Turkey (4), USA (4), Brazil (3), Poland (3), South Korea (3), Spain (3), and other regions (24). Also, 69 studies used ELISA to determine chemokines, 10 studies used Luminex, and 19 studies used other methods. The study quality assessment indicated that NOS scores varied between 5 and 8, with 55 studies classified as moderate quality and 44 classified as high quality.

\section{Main Outcomes}

Table 2 shows the subgroup analysis of chemokines concentrations between T2DM patients and controls; and between PDM participants and controls. Thus, as regards CC chemokines, CCL1 concentrations were compared between 20 T2DM patients and 50 controls. Therefore, concentrations of CCL1 were significantly higher in patients with T2DM than in controls ( $\mathrm{SMD}=0.69$; 95\% CI: 0.28 - 1.09; Figure 1). Besides, no significant heterogeneity was observed in the included studies $\left(I^{2}=0\right)$. Further, CCL2 concentrations were compared between 3,856 T2DM patients and 2,958 controls, and the results indicated that CCL2 concentrations were in patients with T2DM than in the controls $(\mathrm{SMD}=1.51 ; 95 \% \mathrm{CI}: 1.15-1.88$; Figure 1), but with significant heterogeneity $\left(I^{2}=97 \%\right)$. Also, the CCL4 concentrations were compared between 829 T2DM patients and 411 controls. The results showed higher concentrations of CCL4 in T2DM patients than in the controls $(\mathrm{SMD}=1.14$; 95\% CI: 0.51 - 1.78; Figure 1), but with significant heterogeneity $\left(I^{2}=94 \%\right)$. Similarly, the concentrations of CCL5 were compared between 800 T2DM patients and 884 controls, and it was found that these concentrations were higher in T2DM patients than in the controls $(\mathrm{SMD}=1.42 ; 95 \% \mathrm{CI}$ : $0.56-2.29$; Figure 1), but with significant heterogeneity $\left(I^{2}=98 \%\right)$. In addition, CCL11 concentrations were compared between 621 T2DM patients and 793 controls, and the results showed that T2DM patients had higher concentrations of CCL11 than the controls (SMD $=0.77$; 95\% CI: 0.20 - 1.34; Figure 1), but with significant heterogeneity $\left(I^{2}=95 \%\right)$.

Considering CXC chemokines, concentrations of CXCL8 were compared between 1,405 T2DM patients and 1,599 controls, and the results indicated that T2DM patients had higher concentrations of CXCL8 than the controls ( $\mathrm{SMD}=1.18$; 95\% CI: 0.64 - 1.72; Figure 1), but with significant heterogeneity $\left(I^{2}=97 \%\right)$. Additionally, CXCL10 concentrations were compared between 1,116 T2DM patients and 1,461 controls, and the results showed that the concentrations of CXCL10 were higher in patients with $\mathrm{T} 2 \mathrm{DM}$ than the controls $(\mathrm{SMD}=0.87 ; 95 \% \mathrm{CI}$ : 0.32 - 1.42; Figure 1), but with significant heterogeneity $\left(I^{2}=97 \%\right)$. Also, the concentrations of CX3CL1 were compared between 539 T2DM patients and 510 controls, and the results showed higher concentrations of CX3CL1 in patients with T2DM than in the controls $(\mathrm{SMD}=1.45 ; 95 \% \mathrm{CI}: 0.42-2.48$; Figure 1) but with significant heterogeneity $\left(I^{2}=97 \%\right)$. However, when all chemokines concentrations, taken together, were compared between 3,005 PDM patients and 3,541 controls, no significant difference was observed (SMD $=0.20$; 95\% CI: -0.09 0.50; Figure 2). Nevertheless, when specific chemokines concentrations were considered, there were lower concentrations of CCL2 in patients with PDM than in the controls (SMD $=-0.11 ; 95 \% \mathrm{CI}$ : -0.19 - -0.03 ; Figure 2); but there was no significant difference in the concentrations of the following chemokines between patients with PDM and the controls: CCL5 (SMD=0.79; 95\% CI: -0.04 - 1.61; Figure 2), CXCL8 (SMD=0.09; 95\% CI: -0.91 - 1.09; Figure 2), and CXCL10 (SMD=0.10; 95\% CI: -0.57 - 0.77; Figure 2). In addition, funnel plots indicated low probability of publication bias (Appendix 7). Moreover, sensitivity analysis indicated that any single study influenced little change in the SMD of chemokines concentrations in PDM and T2DM. Appendix 8 
TABLE 1 | Characteristics of included studies.

\begin{tabular}{|c|c|c|c|c|c|c|c|}
\hline Study & & Material & Country & NOS & Male gender $n(\%)$ & BMI & Mean Age \\
\hline Adela 2019 & (25) & Serum & India & 7 & $28(52.8 \%)$ & $26.5 \pm 23.5$ & $46.5 \pm 8.5$ \\
\hline Afarideh 2016 & (26) & Venous blood & Iran & 8 & $17(56.6 \%)$ & 26.4 & 54.5 \\
\hline Ahmed 2018 & (27) & Serum & Egypt & 7 & O(0.0\%) & $29.50 \pm 0.05$ & $50.48 \pm 1.38$ \\
\hline Alicka 2019 & (28) & Subcutaneous adipose tissues & Poland & 6 & $6(50.5 \%)$ & $41.50 \pm 5.50$ & 36-69 \\
\hline AlmeidaPititto 2015 & (29) & Blood & Brazil & 7 & NR & $28.1(4.2)$ & $46.8(4.6)$ \\
\hline Alvarado 2018 & (30) & Blood & Sweden & 6 & $6(58.3 \%)$ & NR & $56.3 \pm 11.9$ \\
\hline Aravindhan 2018 & (31) & Serum & India & 8 & $69(65.7 \%)$ & $27 \pm 4$ & $46 \pm 9$ \\
\hline Bala 2010 & (32) & Serum & Germany & 8 & $18(62.1 \%)$ & $31.0 \pm 2.3$ & $61.0 \pm 2.3$ \\
\hline Baldane 2018A & (33) & Venous blood & Turkey & 8 & $36(43.9 \%)$ & $31.1 \pm 5.4$ & $53.6 \pm 9.7$ \\
\hline Baldane 2018B & (34) & Blood & Turkey & 7 & $16(48.4 \%)$ & $27.99 \pm 2.31$ & $50.0 \pm 10.2$ \\
\hline Barchetta 2017 & (35) & Blood & Italy & 8 & $47(66.2 \%)$ & $26.6 \pm 1.8$ & $51.9 \pm 9.2$ \\
\hline Cañizales 2018 & (36) & Plasma & Mexico & 8 & $40(61.5 \%)$ & $30.04 \pm 5.98$ & $50.03 \pm 7.67$ \\
\hline Capone 2015 & (37) & Blood & Italy & 5 & $11(64.7 \%)$ & $24.4 \pm 0.8$ & $61.8 \pm 5.2$ \\
\hline Cha 2012 & (38) & Venous blood & Korea & 8 & $55(47.4 \%)$ & $25.3 \pm 3.11$ & $45.8 \pm 13.8$ \\
\hline Chang 2015 & (39) & Fasting plasma & China & 6 & 22 (52.4\%) & $26.71 \pm 4.77$ & $57.0 \pm 2.0$ \\
\hline Chao 2010 & (40) & Peripheral blood & China & 8 & $57(48.3 \%)$ & $25.9 \pm 4.8$ & $57.6 \pm 10.2$ \\
\hline Chen 2017 & $(41)$ & Aqueous humor & China & 6 & $24(51.0 \%)$ & $22.6 \pm 2.4$ & $58.8 \pm 8.9$ \\
\hline Cheng 2012 & (42) & Serum & China & 8 & $37(67.3 \%)$ & $25.56 \pm 2.47$ & $68.11 \pm 7.53$ \\
\hline Cheung 2012 & $(43)$ & Aqueous humor & Singapore & 6 & 18(66.7\%) & NR & $67.4 \pm 10.7$ \\
\hline Cimini 2017 & (44) & Fasting blood & Italy & 7 & $45(56.9 \%)$ & $33.65 \pm 6.3$ & $58 \pm 9$ \\
\hline Cimini 2018 & $(45)$ & Fasting blood & Italy & 7 & $32(62.8 \%)$ & $29.1 \pm 6.5$ & $58 \pm 11$ \\
\hline Danielsson 2005 & (46) & Blood & Sweden & 5 & $20(100.0 \%)$ & NR & $74 \pm 3$ \\
\hline Davi 2009 & $(47)$ & Blood & Italy & 6 & $51(56.6 \%)$ & $30.7 \pm 1.7$ & $72 \pm 10$ \\
\hline Defast 2000 & (48) & Blood & Canada & 5 & $4(50.0 \%)$ & $29 \pm 3$ & $61 \pm 5$ \\
\hline Degirmenci 2019 & (49) & Serum & Turkey & 6 & $36(48.0 \%)$ & $33.11 \pm 5.29$ & $60.04 \pm 7.72$ \\
\hline Derakhshan 2012 & (50) & Peripheral blood & Iran & 6 & $82(41.0 \%)$ & NR & $40 \pm 9$ \\
\hline Elmesallamy 2011 & (51) & Plasma & Greece & 5 & 13(43.3\%) & $20.65 \pm 0.95$ & $11.47 \pm 0.66$ \\
\hline Feng 2016 & (52) & Blood & China & 7 & $19(76.0 \%)$ & $26.46 \pm 4.60$ & $53.76 \pm 8.89$ \\
\hline Funatsu 2009 & (53) & Vitreous fluid & Japan & 6 & $25(47.2 \%)$ & NR & $61.2 \pm 7.2$ \\
\hline Geerlings 2000 & (54) & Blood & the Netherlands & 6 & $\mathrm{O}(0.0 \%)$ & NR & $45 \pm 4$ \\
\hline Giulietti 2006 & (55) & Blood & Belgium & 6 & $6(46.15 \%)$ & $31.3 \pm 4.5$ & $62 \pm 4$ \\
\hline Gokulakrishnan 2015 & (56) & Serum & India & 7 & $25(50.0 \%)$ & $22.3 \pm 2.0$ & $20.1 \pm 3.2$ \\
\hline Gómez 2008 & $(57)$ & Blood & Spain & 8 & $12(40.0 \%)$ & $28.6 \pm 2.5$ & $48.5 \pm 5.8$ \\
\hline Gong 2016 & (58) & Serum & China & 6 & $35(60.3 \%)$ & $23.86 \pm 2.26$ & $61.16 \pm 14.38$ \\
\hline Hamid 2016 & (59) & Blood & Pakistan & 7 & $17(51.5 \%)$ & $26.00 \pm 3.70$ & $64.18 \pm 3.31$ \\
\hline Hara 2016 & (60) & Blood & Brazil & 5 & $\mathrm{O}(0.0 \%)$ & $31.66 \pm 6.96$ & $32.55 \pm 5.94$ \\
\hline He 2014 & $(61)$ & Venous peripheral blood & China & 5 & 6(60.0\%) & $28.0 \pm 6.7$ & $32 \pm 7$ \\
\hline Herder 2005 & (62) & Blood & Germany & 8 & $137(58.0 \%)$ & $30.9 \pm 4.5$ & $65.1 \pm 5.1$ \\
\hline Herder 2008 & (63) & Blood & Germany & 8 & $137(58.0 \%)$ & $30.9 \pm 4.5$ & $65.1 \pm 5.1$ \\
\hline Hernández 2008 & (64) & Vitreous fluid & Spain & 5 & $9(40.9 \%)$ & NR & $68 \pm 5$ \\
\hline Hirsch 2012 & $(65)$ & Blood & Brazil & 6 & $7(15.3 \%)$ & $44.8 \pm 7.8$ & $55.7 \pm 1.2$ \\
\hline Hu 2012 & (66) & Blood & China & 7 & $21(47.7 \%)$ & $24.02 \pm 3.46$ & $52.56 \pm 9.40$ \\
\hline Huang 2012 & (67) & Serum & China & 5 & $108(54.0 \%)$ & NR & $56.7 \pm 3.0$ \\
\hline Inayat 2019 & (68) & Blood & Pakistan & 6 & 18(52.9\%) & $28 \pm 19$ & $46 \pm 3$ \\
\hline Kalninova 2014 & (69) & Plasma & Slovakia & 7 & NR & $28.9 \pm 7.3$ & $63.00 \pm 8.50$ \\
\hline Kang 2010 & (70) & Plasma & South Korea & 8 & $41(45.0 \%)$ & $25.5 \pm 3.21$ & $53.8 \pm 10.8$ \\
\hline Kou 2018 & $(71)$ & Blood & China & 7 & $51(54.8 \%)$ & $25.47 \pm 3.32$ & $60.15 \pm 12.32$ \\
\hline Kumar 2012 & (72) & Pancreata & India & 6 & 13(56.5\%) & NR & $38.1 \pm 9.2$ \\
\hline Kumar 2013 & (73) & Plasma & India & 7 & $31(70.5 \%)$ & $23.90 \pm 9.56$ & $45 \pm 3$ \\
\hline LandersRamos 2019 & $(74)$ & Aqueous humor & Korea & 5 & $30(46.9 \%)$ & NR & $56.81 \pm 7.96$ \\
\hline Lareyre 2018 & (75) & Plasma & France & 5 & NR & $25.8 \pm 4.4$ & $73 \pm 5$ \\
\hline Li 2019 & (76) & Blood & China & 8 & $108(49.31 \%)$ & $25.04 \pm 2.47$ & $44.64 \pm 8.53$ \\
\hline Liu 2011 & (77) & Tears & China & 6 & 8(53.3\%) & NR & $61.07 \pm 2.16$ \\
\hline Liu 2012 & (78) & Blood & China & 7 & $21(65.6 \%)$ & $24.37 \pm 3.93$ & $51.97 \pm 16.57$ \\
\hline Liuni 2015 & (79) & Blood & India & 6 & 9(30.0\%) & $27.5 \pm 4.03$ & $73.4 \pm 11.2$ \\
\hline Lu 2017 & (80) & $\begin{array}{l}\text { Peripheral blood mononuclear cell、 Heparinized } \\
\text { venous blood、 plasma }\end{array}$ & China & 6 & $22(73.3 \%)$ & NR & $54.20 \pm 3.86$ \\
\hline Maegdefessel 2010 & $(81)$ & Blood & Germany & 5 & $37(78.0 \%)$ & $28.2 \pm 5$ & $64.0 \pm 9$ \\
\hline Maier 2008 & (82) & Serum & Australia & 5 & $15(41.6 \%)$ & NR & $66.2 \pm 12.2$ \\
\hline Mangialardi 2019 & (83) & Bone marrow & UK & 5 & $7(50.0 \%)$ & $33 \pm 2$ & $67 \pm 3$ \\
\hline McCarthy 2019 & (84) & Blood & USA & 5 & $70(74.5 \%)$ & NR & $68 \pm 11.3$ \\
\hline Mesia 2016 & (85) & Peripheral blood & USA & 5 & $6(60.0 \%)$ & $36.4 \pm 10.95$ & $61.3 \pm 5.4$ \\
\hline Mine 2008 & (86) & Peripheral blood & Japan & 6 & $55(51.9 \%)$ & $23.7 \pm 3.4$ & $65.2 \pm 9.6$ \\
\hline
\end{tabular}


TABLE 1 | Continued

\begin{tabular}{|c|c|c|c|c|c|c|c|}
\hline Study & & Material & Country & NOS & Male gender $n(\%)$ & BMI & Mean Age \\
\hline Mohamed 2015 & (87) & Blood & Norway & 5 & $7(29.2 \%)$ & NR & $50.79 \pm 2.05$ \\
\hline Murase 2012 & (88) & Blood & Japan & 6 & $78(63.4 \%)$ & $24.3 \pm 4.2$ & $62.9 \pm 7.8$ \\
\hline Nomura 2005 & (89) & Blood & Japan & 7 & $12(42.9 \%)$ & $23.7 \pm 3.8$ & $65 \pm 11$ \\
\hline Omoto 2015 & (90) & Blood & Japan & 6 & $60(53.1 \%)$ & $26.1 \pm 3.9$ & $62 \pm 6$ \\
\hline Papatheodorou 2012 & (91) & Blood & Greece & 8 & $96(48.2 \%)$ & $31.24 \pm 5.1$ & $65.6 \pm 9.2$ \\
\hline Pham 2012 & (92) & Serum & Germany & 5 & $263(56.5 \%)$ & $30.3 \pm 7.0$ & $56.3 \pm 8.1$ \\
\hline Porta 2018 & (93) & Blood & Italy & 6 & $11(52.3 \%)$ & $27.00 \pm 4.00$ & $63.00 \pm 9.00$ \\
\hline Prechel 2018 & (94) & Blood specimens & USA & 5 & 20 (40.0\%) & 35.1 & 57.52 \\
\hline Pushpanathan 2016 & (95) & Blood & India & 5 & NR & $30.3 \pm 5.16$ & $51.52 \pm 13.69$ \\
\hline Ruotsalainen 2010 & (96) & Blood & Finland & 6 & $8(40 \%)$ & $28.0 \pm 6.2$ & $38.6 \pm 6.6$ \\
\hline Sajadi 2013 & (97) & Peripheral blood & Iran & 6 & $41(41.0 \%)$ & NR & $40 \pm 9$ \\
\hline Samaras 2010 & (98) & $\begin{array}{l}\text { Paired of subcutaneous (SAT) and visceral } \\
\text { adipose tissue(VAT) }\end{array}$ & Australia & 8 & NR & $35.0 \pm 3.2$ & $62 \pm 8$ \\
\hline Sathishkumar 2016 & (99) & Blood & India & 8 & $16(64 \%)$ & $26.6 \pm 4.3$ & $45.0 \pm 9$ \\
\hline Saukkonen 2018 & $(100)$ & Venous blood & Finland & 7 & NR & $27.9 \pm 3.5$ & $62.1 \pm 0.7$ \\
\hline Shah 2011 & (101) & Blood & USA & 5 & NR & NR & NR \\
\hline Sindhu 2016 & (102) & Plasma & Kuwait & 7 & NR & $32.68 \pm 4.63$ & $50.92 \pm 6.42$ \\
\hline Sindhu 2017 & $(12)$ & Plasma & Kuwait & 7 & NR & $32.68 \pm 4.63$ & $50.92 \pm 6.42$ \\
\hline Sozer 2014 & (103) & Blood & Turkey & 7 & 29(48.3\%) & $27.57 \pm 4.09$ & $52.96 \pm 12.64$ \\
\hline Tavangar 2016 & $(104)$ & Fasting blood & Iran & 6 & NR & NR & NR \\
\hline Tavangar 2017 & (105) & Salivary & Iran & 6 & NR & $\mathrm{NR}$ & NR \\
\hline Toan 2018 & $(106)$ & Serum & Vietnam & 7 & $29(58.0 \%)$ & $26.7 \pm 5.3$ & $59 \pm 4$ \\
\hline Tokarz 2016 & (107) & Blood & Poland & 6 & $29(60.4 \%)$ & $31.18 \pm 5.21$ & $63.02 \pm 9.92$ \\
\hline Tvarijonaviciute 2017 & $(108)$ & Salivary & Spain & 5 & $14(45.2 \%)$ & $26.4 \pm 5.4$ & $49.8 \pm 20.9$ \\
\hline Umapathy 2018 & (109) & Fasting blood & India & 8 & NR & $27.14 \pm 3.35$ & $54.07 \pm 11.09$ \\
\hline Wada 2000 & $(110)$ & Serum & Japan & 5 & $32(71.1 \%)$ & NR & $61.1 \pm 4.2$ \\
\hline Wang 2019 & $(111)$ & Whole blood & China & 5 & $48(69.57 \%)$ & $25.61 \pm 5.76$ & $64.29 \pm 3.77$ \\
\hline Wei 2013 & $(112)$ & Venous blood & China & 6 & 14(70.0\%) & $25.19 \pm 4.01$ & $60.6 \pm 9.61$ \\
\hline Wender 2008 & $(11)$ & Venous blood & Poland & 6 & $0(0.0 \%)$ & $21.5 \pm 9.0$ & $28.8 \pm 1.5$ \\
\hline Wu 2014 & $(113)$ & Blood & China & 7 & $82(45.5 \%)$ & $25.85 \pm 2.60$ & $52.58 \pm 5.96$ \\
\hline Xu 2015 & $(114)$ & Forearm venous blood & China & 8 & $36(72.0 \%)$ & $24.77 \pm 2.67$ & $56.83 \pm 12.48$ \\
\hline Yadav 2017 & $(115)$ & Blood & UK & 6 & NR & $53 \pm 9$ & NR \\
\hline Yang 2012 & $(116)$ & Venous blood & China & 8 & $15(53.5 \%)$ & $22.4 \pm 3.1$ & $52 \pm 8$ \\
\hline Yi 2014 & $(117)$ & Blood & China & 8 & $20(52.6 \%)$ & $23.65 \pm 2.89$ & $59.52 \pm 14.14$ \\
\hline Zeng 2019 & (118) & Vitreous humor & China & 7 & $10(50.0 \%)$ & NR & $55.63 \pm 7.64$ \\
\hline Zhang 2015 & (119) & Abdominal omental adipose tissues & China & 6 & $3(50.0 \%)$ & $36.27 \pm 2.97$ & $50 \pm 6$ \\
\hline Zhou 2016 & $(120)$ & Blood & China & 7 & $14(36.7 \%)$ & $25.4 \pm 5.4$ & $59.0 \pm 10.5$ \\
\hline
\end{tabular}

NR, not report; BMI, Body Mass Index; USA, United States of America; UK, United Kingdom.

shows in more detail results of the analysis of the chemokines concentration differences between patients with T2DM or PDM and the controls.

Considering subgroups according to gender, the results indicated that concentrations of chemokines in the female T2DM patients (SMD=1.11; 95\% CI: 0.79 - 1.43; Table 3) and male T2DM patients $(\mathrm{SMD}=1.11 ; 95 \% \mathrm{CI}: 0.87-1.35$; Table 3) were significantly higher than in the controls. However, no significant difference was observed in the male PDM participants (SMD $=-0.02$; 95\% CI: $-0.41-0.37$; Table 3). Furthermore, subgroup analysis indicated that the concentrations of chemokines were higher in the over 60 years old with T2DM than in their counterparts forming the control group $(\mathrm{SMD}=1.39$; 95\% CI: 1.12 - 1.65; Table 3). Similarly, the concentrations of chemokines were higher in the under 60 years old with T2DM than in their counterparts forming the control group ( $\mathrm{SMD}=0.95 ; 95 \% \mathrm{CI}$ : $0.69-1.22$; Table 3) in T2DM, but with a lower effect value (SMD) than in the over 60 years old group. However, no significant difference was observed in the PDM participants as regards to age differences. Considering methods for measuring chemokines (Luminex method and ELISA method subgroups), subgroup analysis indicated that the T2DM patients had higher concentrations of chemokines than the controls, when chemokines were measured using the Luminex method $(\mathrm{SMD}=0.71 ; 95 \% \mathrm{CI}: 0.14-1.28$; Table 3$)$ and the ELISA method ( $\mathrm{SMD}=1.32$; 95\% CI:1.05 - 1.59; Table 3). However, no significant difference was observed between the PDM participants and the controls when the ELISA method was used (SMD=0.17; 95\% CI: -0.20 - 0.55; Table 3).

\section{DISCUSSION}

To the best of our knowledge, this is the first systematic review and meta-analysis to explore the association between chemokines concentrations and T2DM/PDM. We identified and systematically reviewed 98 studies. We found that the concentrations of CC chemokines (e.g. CCL1, CCL2, CCL4, CCL5 and CCL11), CXC chemokines (e.g. CXCL8 and 


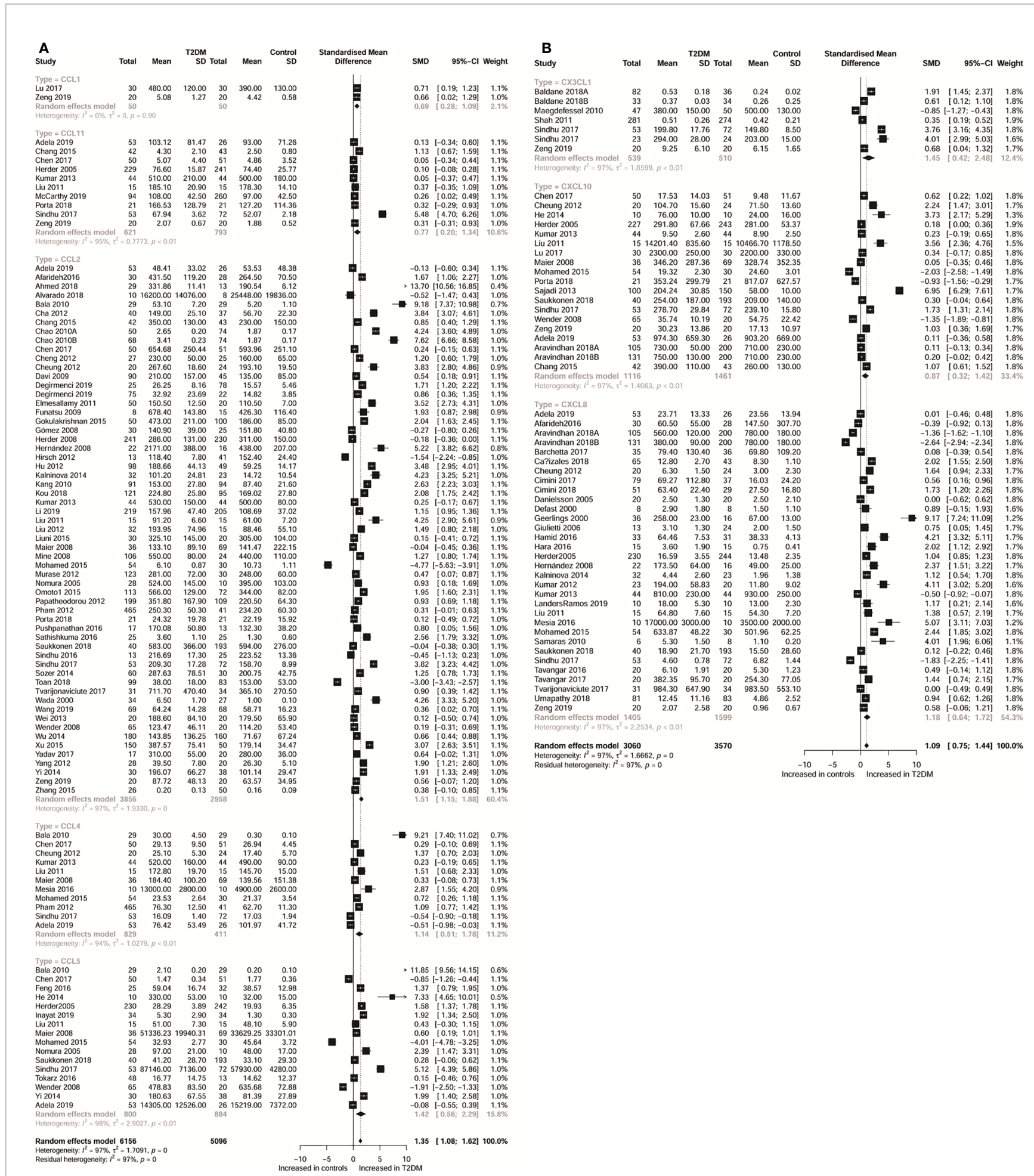

FIGURE 1 | Forest plot of CC chemokine (A) and CXC chemokine (B) between T2DM patients and controls. Study effect sizes of chemokines differences between T2DM and controls. Each data marker represents a study, and the size of the data marker is proportional to the total number of individuals in that study. The summary effect size for each chemokines is denoted by a diamond. T2DM, type 2 diabetes mellitus; SMD, standardized mean difference. 


\begin{tabular}{|c|c|c|c|c|c|c|c|c|c|c|}
\hline \multirow[b]{2}{*}{ Study } & \multirow[b]{2}{*}{ Total } & \multicolumn{3}{|c|}{ PDM } & \multicolumn{2}{|r|}{ Control } & \multirow{2}{*}{$\begin{array}{l}\text { Standardised Mean } \\
\text { Difference }\end{array}$} & \multirow[b]{2}{*}{ SMD } & \multirow[b]{2}{*}{$95 \%-\mathrm{Cl}$} & \multirow[b]{2}{*}{ Weight } \\
\hline & & Mean & SD & Total & Mean & SD & & & & \\
\hline \multicolumn{11}{|l|}{ Type = CCL11 } \\
\hline Herder 2005 & 229 & 74.30 & 13.85 & 241 & 74.40 & 25.77 & & -0.00 & {$[-0.19 ; 0.18]$} & $5.8 \%$ \\
\hline $\begin{array}{l}\text { Random effects model } \\
\text { Heterogeneity: not applicable }\end{array}$ & 229 & & & 241 & & & & -0.00 & {$[-0.19 ; 0.18]$} & $5.8 \%$ \\
\hline \multicolumn{11}{|l|}{ Type = CCL2 } \\
\hline AlmeidaPititto 2015 & 440 & 32.20 & 18.70 & 337 & 35.90 & 21.20 & & -0.19 & {$[-0.33 ;-0.04]$} & $5.9 \%$ \\
\hline AlmeidaPititto 2015 & 221 & 34.10 & 18.60 & 337 & 35.90 & 21.20 & & -0.09 & {$[-0.26 ; 0.08]$} & $5.8 \%$ \\
\hline Herder 2008 & 240 & 312.00 & 98.00 & 230 & 311.00 & 112.00 & & 0.01 & {$[-0.17 ; 0.19]$} & $5.8 \%$ \\
\hline Herder 2008 & 241 & 286.00 & 131.00 & 230 & 311.00 & 150.00 & & -0.18 & {$[-0.36 ; 0.00]$} & $5.8 \%$ \\
\hline Saukkonen 2018 & 82 & 596.00 & 275.00 & 193 & 594.00 & 276.00 & & 0.01 & {$[-0.25 ; 0.27]$} & $5.7 \%$ \\
\hline $\begin{array}{l}\text { Random effects model } \\
\text { Heterogeneity: } I^{2}=4 \%, \tau^{2}=\end{array}$ & $\begin{array}{l}1224 \\
=0.000\end{array}$ & $4, p=0$ & & 1327 & & & & -0.11 & {$[-0.19 ;-0.03]$} & $29.1 \%$ \\
\hline \multicolumn{11}{|l|}{ Type = CCL5 } \\
\hline Herder 2005 & 230 & 25.96 & 2.99 & 242 & 19.93 & 6.35 & & 1.20 & {$[1.01 ; 1.40]$} & $5.8 \%$ \\
\hline Saukkonen 2018 & 82 & 43.30 & 26.00 & 193 & 33.10 & 29.30 & & 0.36 & {$[0.10 ; 0.62]$} & $5.7 \%$ \\
\hline \multicolumn{11}{|c|}{ Heterogeneity: $I^{2}=96 \%, \tau^{2}=0.3429, p<0.01$} \\
\hline \multicolumn{11}{|l|}{ Type = CX3CL1 } \\
\hline Baldane 2018 & 34 & 0.61 & 0.35 & 36 & 0.24 & 0.02 & + & 1.50 & [0.96; 2.03] & $5.0 \%$ \\
\hline $\begin{array}{l}\text { Random effects model } \\
\text { Heterogeneity: not applicable }\end{array}$ & 34 & & & 36 & & & & 1.50 & {$[0.96 ; 2.03]$} & $5.0 \%$ \\
\hline \multicolumn{11}{|l|}{ Type = CXCL10 } \\
\hline Herder 2005 & 227 & 310.20 & 53.51 & 243 & 281.00 & 53.37 & & 0.55 & {$[0.36 ; 0.73]$} & $5.8 \%$ \\
\hline Saukkonen 2018 & 82 & 251.00 & 179.00 & 193 & 209.00 & 140.00 & & 0.27 & [ $0.02 ; 0.53]$ & $5.7 \%$ \\
\hline Aravindhan 2018 & 185 & 620.00 & 80.00 & 200 & 710.00 & 230.00 & & -0.51 & {$[-0.72 ;-0.31]$} & $5.8 \%$ \\
\hline \multicolumn{11}{|c|}{ Heterogeneity: $I^{2}=97 \%, \tau^{2}=0.3377, p<0.01$} \\
\hline \multicolumn{11}{|l|}{ Type = CXCL12 } \\
\hline Aravindhan 2018 & 185 & 2.10 & 0.20 & 200 & 1.80 & 0.50 & & 0.78 & {$[0.57 ; 0.98]$} & $5.8 \%$ \\
\hline $\begin{array}{l}\text { Random effects model } \\
\text { Heterogeneity: not applicable }\end{array}$ & $e^{185}$ & & & 200 & & & $\bullet$ & 0.78 & {$[0.57 ; 0.98]$} & $5.8 \%$ \\
\hline \multicolumn{11}{|l|}{ Type = CXCL8 } \\
\hline Aravindhan 2018 & 185 & 510.00 & 100.00 & 200 & 780.00 & 180.00 & & -1.83 & {$[-2.07 ;-1.59]$} & $5.7 \%$ \\
\hline Herder 2005 & 230 & 13.52 & 3.22 & 244 & 13.48 & 2.35 & & 0.01 & {$[-0.17 ; 0.19]$} & $5.8 \%$ \\
\hline LandersRamos 2019 & 10 & 17.00 & 5.50 & 10 & 13.00 & 2.30 & & 0.91 & {$[-0.02 ; 1.84]$} & $3.7 \%$ \\
\hline Ruotsalainen 2010 & 20 & 1.10 & 0.50 & 19 & 0.50 & 0.30 & & 1.42 & {$[0.71 ; 2.13]$} & $4.4 \%$ \\
\hline Saukkonen 2018 & 82 & 20.50 & 26.00 & 193 & 15.50 & 28.60 & + & 0.18 & {$[-0.08 ; 0.44]$} & $5.7 \%$ \\
\hline $\begin{array}{l}\text { Random effects model } \\
\text { Heterogeneity: } I^{2}=98 \%, \tau^{2}=\end{array}$ & $\begin{aligned} & \mathbf{5 2 7} \\
= & 1.22\end{aligned}$ & $p<0.0$ & & 666 & & & & 0.09 & {$[-0.91 ; 1.09]$} & $25.5 \%$ \\
\hline \multirow{3}{*}{$\begin{array}{l}\text { Random effects model } \\
\text { Heterogeneity: } I^{2}=97 \%, \tau^{2}\end{array}$} & 3005 & & & 3541 & & & $b$ & 0.20 & {$[-0.09 ; 0.50]$} & $100.0 \%$ \\
\hline & $=0.38$ & $312, p<0$ & & & & & 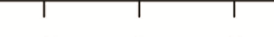 & & & \\
\hline & & & & & & Increa & $\begin{array}{lrr}-5 & 0 & 5 \\
\text { controls } & \text { Increase }\end{array}$ & $\begin{array}{l}10 \\
\text { PDM }\end{array}$ & & \\
\hline
\end{tabular}

FIGURE 2 | Forest plot of chemokine between PDM patients and controls. Study effect sizes of chemokines differences between PDM and controls. Each data marker represents a study, and the size of the data marker is proportional to the total number of individuals in that study. The summary effect size for each chemokines is denoted by a diamond. PDM, prediabetes diabetes mellitus; SMD, standardized mean difference.

CXCL10) and CX3CL1 chemokines were significantly higher in patients with T2DM than in the controls. However, no significant difference in these concentrations was observed between patients with PDM and the controls. These results suggest that some chemokines may play a key role in modulating the pathological process of the progression of PDM to T2DM. Exploring the role of unique chemokines, produced from the immune system, could help to provide a novel therapeutic target for T2DM.

Inflammation appears to be involved in the interplay among chemokines and progression of T2DM, as this has been shown in other several pathological conditions (121-124). Moreover, recent reviews suggested that chemokines, CXCL10, CXCL9, and CXCL11, are implicated in the pathogenesis of 
TABLE 2 | Subgroup analysis of chemokines between T2DM and PDM participants and controls.

\begin{tabular}{|c|c|c|c|c|c|c|c|}
\hline & \multirow[t]{2}{*}{$\mathbf{N}$} & \multirow[t]{2}{*}{ SMD } & \multirow[t]{2}{*}{$95 \%-\mathrm{Cl}$} & & \multicolumn{3}{|c|}{ Heterogeneity } \\
\hline & & & & & $\mathbf{Q}$ & $\tau^{2}$ & $\mathbf{I}^{2}$ \\
\hline \multicolumn{8}{|c|}{ CC chemokines in T2DM } \\
\hline CCL1 & 2 & 0.69 & 0.28 & 1.09 & 0.02 & 0.00 & $0.00 \%$ \\
\hline CCL11 & 10 & 0.77 & 0.20 & 1.34 & 191.59 & 0.78 & $95.30 \%$ \\
\hline CCL13 & 1 & 0.38 & -0.24 & 1.01 & 0.00 & - & - \\
\hline CCL15 & 1 & 1.26 & 0.58 & 1.95 & 0.00 & - & - \\
\hline CCL19 & 2 & -0.08 & -1.33 & 1.18 & 5.11 & 0.66 & $80.40 \%$ \\
\hline CCL2 & 59 & 1.51 & 1.15 & 1.88 & 2123.05 & 1.93 & $97.30 \%$ \\
\hline CCL20 & 2 & 2.09 & -0.55 & 4.72 & 42.62 & 3.53 & $97.70 \%$ \\
\hline CCL21 & 1 & 0.58 & -0.06 & 1.21 & 0.00 & - & - \\
\hline CCL22 & 2 & -0.54 & -2.89 & 1.82 & 38.18 & 2.82 & $97.40 \%$ \\
\hline CCL23 & 3 & 0.33 & -0.12 & 0.79 & 2.56 & 0.04 & $22.00 \%$ \\
\hline CCL24 & 2 & 0.34 & -2.01 & 2.70 & 29.10 & 2.78 & $96.60 \%$ \\
\hline CCL25 & 1 & 0.40 & -0.23 & 1.03 & 0.00 & - & - \\
\hline CCL26 & 1 & 0.76 & 0.12 & 1.40 & 0.00 & - & - \\
\hline CCL27 & 1 & 0.82 & 0.17 & 1.47 & 0.00 & - & - \\
\hline CCL3 & 10 & 1.18 & -0.07 & 2.44 & 534.93 & 3.78 & $98.30 \%$ \\
\hline CCL4 & 11 & 1.14 & 0.51 & 1.78 & 178.98 & 1.03 & $94.40 \%$ \\
\hline CCL5 & 16 & 1.42 & 0.56 & 2.29 & 670.89 & 2.90 & $97.80 \%$ \\
\hline CCL7 & 2 & -1.83 & -5.43 & 1.76 & 71.34 & 6.62 & $98.60 \%$ \\
\hline CCL8 & 1 & 0.84 & 0.19 & 1.49 & 0.00 & - & - \\
\hline \multicolumn{8}{|c|}{ CXC chemokines in T2DM } \\
\hline CX3CL1 & 7 & 1.45 & 0.42 & 2.48 & 237.68 & 1.86 & $97.5 \%$ \\
\hline CXCL1 & 5 & 1.48 & -0.86 & 3.83 & 406.74 & 7.08 & $99.0 \%$ \\
\hline CXCL10 & 19 & 0.87 & 0.32 & 1.42 & 643.86 & 1.41 & $97.2 \%$ \\
\hline CXCL11 & 2 & 2.81 & -2.19 & 7.80 & 67.38 & 12.78 & $98.5 \%$ \\
\hline CXCL12 & 8 & 0.60 & -0.89 & 2.08 & 683.75 & 4.46 & $99.0 \%$ \\
\hline CXCL13 & 1 & 0.61 & -0.03 & 1.25 & 0.00 & - & - \\
\hline CXCL16 & 2 & 1.97 & -2.27 & 6.21 & 58.43 & 9.20 & $98.3 \%$ \\
\hline CXCL2 & 1 & 0.00 & -0.62 & 0.62 & 0.00 & - & - \\
\hline CXCL4 & 1 & 0.78 & 0.37 & 1.18 & 0.00 & - & - \\
\hline CXCL5 & 1 & -0.74 & -1.39 & -0.10 & 0.00 & - & - \\
\hline CXCL6 & 1 & 1.09 & 0.42 & 1.75 & 0.00 & - & - \\
\hline CXCL8 & 32 & 1.18 & 0.64 & 1.72 & 1172.62 & 2.25 & $97.4 \%$ \\
\hline CXCL9 & 3 & 0.05 & -0.86 & 0.97 & 12.25 & 0.54 & $83.7 \%$ \\
\hline \multicolumn{8}{|c|}{ Chemokines in PDM } \\
\hline CCL11 & 1 & 0.00 & -0.19 & 0.18 & 0.00 & - & - \\
\hline CCL2 & 5 & -0.11 & -0.19 & -0.03 & 4.17 & 0.00 & $4.10 \%$ \\
\hline CCL5 & 2 & 0.79 & -0.04 & 1.61 & 25.81 & 0.34 & $96.10 \%$ \\
\hline CX3CL1 & 1 & 1.50 & 0.96 & 2.03 & 0.00 & - & - \\
\hline CXCL10 & 3 & 0.10 & -0.57 & 0.77 & 59.20 & 0.34 & $96.60 \%$ \\
\hline CXCL12 & 1 & 0.78 & 0.57 & 0.98 & 0.00 & - & - \\
\hline CXCL8 & 5 & 0.09 & -0.91 & 1.09 & 210.62 & 1.22 & $98.10 \%$ \\
\hline
\end{tabular}

Heterogeneity was quantified using $l^{2}$ and its significance was tested using the Q statistics. SMD, standardized mean difference; DF, degrees of Freedom; T2DM, Type-2 diabetes mellitus; PDM, prediabetes.

autoimmune diseases such as autoimmune thyroiditis, type 1 diabetes, Graves disease, Thyroid eye disease, and Addison's disease (125-128). Also, evidence indicates CCL2 and CXCL10 chemokine modulations by cytokines and PPAR $\gamma$ agonist in Graves' ophthalmopathy (129). In this regard, PPAR $\gamma$ agonist activation plays an inhibitory role on CXCL10, but stimulates the release of CCL2. Moreover, a recent systematic review and metaanalysis suggested that chemokines, CCL3, CCL4, CCL5, CCL20, CXCL8 and CXCL11, are implicated in the pathogenesis of nonalcoholic fatty liver disease, post-traumatic stress disorder, and also different types of cancers (130-133).

The chemokines system plays a variety of roles in the T2DM microenvironment. Pancreatic islets and peri-pancreatic adipose tissue (PAT) are exposed to an early damage by genetic or environmental factors and start to secrete numerous proinflammatory chemokines. The chemokines and their receptors can also cause a variety of immune cells to enter the pancreatic islets and PAT site to play the role of immune attack. Proinflammatory chemokines are bound to their receptors; hence activating the nuclear factor-kappaB $(\mathrm{NF}-\kappa \mathrm{B} / \mathrm{I} \kappa \mathrm{B} \alpha)$, and Adenosine 5-monophosphate-activated protein kinase (AMPK) activation pathway, which stimulates a proinflammatory condition. Free fatty acid may also activate inflammatory pathways that may lead to DNA damage.

Moreover, dysfunction of free fatty acid can lead to superoxide and subsequent hydrogen peroxide, which can combine with nitric oxide, such as peroxynitrite (ONOO-), to create peroxynitrite. The compromised mitochondrial electron 
TABLE 3 | Subgroup analysis of chemokines between T2DM and PDM participants and controls.

\begin{tabular}{|c|c|c|c|c|c|c|c|}
\hline \multirow[t]{2}{*}{ Subgroup } & & \multirow[t]{2}{*}{ SMD } & \multirow[t]{2}{*}{$95 \%-\mathrm{Cl}$} & & \multicolumn{3}{|c|}{ Heterogeneity } \\
\hline & & & & & $\mathbf{Q}$ & $\tau^{2}$ & $\mathbf{I}^{2}$ \\
\hline \multicolumn{8}{|l|}{ T2DM } \\
\hline \multirow[t]{2}{*}{ Gender } & Female & 1.11 & 0.79 & 1.43 & 4524.88 & 2.76 & 0.98 \\
\hline & Male & 1.11 & 0.87 & 1.35 & 3172.76 & 1.37 & 0.97 \\
\hline \multirow[t]{2}{*}{ Age } & $>60$ & 1.39 & 1.12 & 1.65 & 1572.77 & 1.11 & 0.96 \\
\hline & $\leq 60$ & 0.95 & 0.69 & 1.22 & 6193.05 & 2.43 & 0.98 \\
\hline \multirow[t]{3}{*}{ Method } & ELISA & 1.32 & 1.05 & 1.59 & 5246.49 & 2.05 & 0.98 \\
\hline & Luminex & 0.71 & 0.14 & 1.28 & 1854.35 & 3.04 & 0.98 \\
\hline & Other & 0.95 & 0.71 & 1.19 & 586.75 & 0.74 & 0.90 \\
\hline \multicolumn{8}{|l|}{ PDM } \\
\hline \multirow[t]{2}{*}{ Gender } & Female & 0.55 & 0.22 & 0.88 & 36.38 & 0.15 & 0.84 \\
\hline & Male & -0.02 & -0.41 & 0.37 & 494.19 & 0.43 & 0.98 \\
\hline \multirow[t]{2}{*}{ Age } & $>60$ & 0.24 & 0.02 & 0.51 & 146.96 & 0.17 & 0.94 \\
\hline & $\leq 60$ & 0.19 & 0.41 & 0.79 & 339.84 & 0.70 & 0.98 \\
\hline \multirow[t]{2}{*}{ Method } & ELISA & 0.17 & -0.20 & 0.55 & 538.33 & 0.45 & 0.98 \\
\hline & Luminex & 0.23 & 0.06 & 0.39 & 6.06 & 0.01 & 0.34 \\
\hline
\end{tabular}

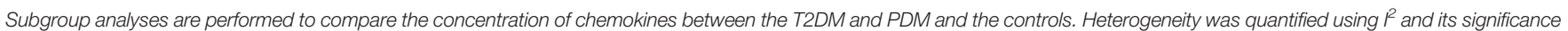
was tested using the Q statistics. NR, not report; T2DM, Type-2 diabetes mellitus; PDM, prediabetes; ELISA, Enzyme linked immunosorbent assay; SMD, standardized mean difference.

transport chain (ETC) and the reducing adenosine triphosphate (ATP) synthesis will further lead to the production of reactive oxygen species/reactive nitrogen species (ROS/RNS).

All these processes impact the endoplasmic reticulum (ER) stress, leading to a reduction in the ability to secrete insulin. Moreover, T2DM progression is characterized by progressive secretion of pro-inflammatory chemokines/cytokines caused by $\beta$ cell damage. Due to this process, various immune cell types (i.e., neutrophils, macrophages, Natural killer (NK) cell, dendritic cell and specifically $\mathrm{T}$ cells) are recruited in the pancreatic tissue. These immune cells further release more innate inflammatory cytokines, which contribute to $\beta$ cell death (Figure 3).

Further, studies have shown that the progression of T2DM is often accompanied by chronic silent inflammation $(6,134)$. Thus, various pro-inflammatory chemokines mediators are involved in the pathogenesis of T2DM, and this may further alter the normal structure of $\beta$-cells by inducing pancreatic islet's apoptosis (134). Therefore, it may be suggested that the association between T2DM and chemokines may be bidirectional (7).

Referring to higher concentrations of CCL1 in patients with T2DM than in controls, a previous study suggested that CCL1 attracts monocytes, macrophages, Th2 cells and Treg cells by interacting with cell surface chemokine receptor CCR8 (135). Among these monocytes, macrophages release a variety of proinflammatory cytokines (IL-1 $\beta$ and IL-6), which can be released into the systemic circulation (136). Besides, IL-1 $\beta$ can induce inflammation by binding to interleukin-1 receptor type I, which reduces the expression of insulin receptor substrate-1 (IRS-1) at the ERK-dependent transcriptional level and ERKindependent post-transcriptional level, resulting in impaired insulin secretion of islet $\beta$ cells (137). Moreover, the mechanism of IR induced by IL- 6 is complex in that it could not only suppress the lipoprotein lipase that consecutively increase the plasma levels of triglycerides, but could also prevent the metabolism of non-oxidative glucose (138). This is consistent with our result that CCL1 may play a decisive role during immunoregulation in the pathogenesis of T2DM.

Furthermore, in relation to the findings of this study, CCL2, CCL4, CCL5 and CCL11 are considered as pro-inflammatory chemokines. For example, the CCL2 is a chemokine specifically for CCR2 receptors, whereas the CCL4, CCL5 and CCL11 exert a wide range of activities through the CCR5 receptors (139). Among the various chemokine receptors, CCR2, and CCR5 are the most important receptors that play a central role in the pathogenesis of T2DM, and this is consistent with our results. Also, Szalai et al. found that a polymorphism in CCR2 expression has been associated with the progression of IR in children (140). In addition, it has been found that fat cells can secrete CCR2 in an inactive form. Activated CCR2 can induce the expression of various inflammatory genes and reduce insulin-dependent glucose uptake. Further, adipocytes can also secrete CCL2 and CCL3, which is an effective signal for macrophage recruitment (141).

Also, upregulation of CCL2 and CCL3 by adipocytes may contribute to the progression of IR in adipose tissue and peripheral tissues. Although the results showed lower concentrations of CCL2 in PDM than in the controls, the effect value was low. Therefore, future studies need to further explore the dose-response relationship and specific pathophysiological role of CCL2 in the pathogenesis, severity and progression of PDM. In addition, Chang et al. found that CCL4 and CCR5 might provide potential therapeutic targets in T2DM (142). With the dysfunction of $\beta$ cells in T2DM, even before $\beta$ cells are widely damaged, the CCL4 concentrations may rise ahead of time. Also, while there are $\beta$ cells death and early islet graft loss, inflammatory stimuli with a CD40-CD40L interaction could induce the secretion of CCL4 through the Raf/MEK/ERK and NF- $\kappa B$ pathways in pancreatic islets (143). Therefore, CCL4 concentrations may be caused by the initial inflammatory damage of islet $\beta$ cells.

As a member of the CXC chemokine family, the function of CXCL8 is to induce chemotaxis in its target cells, like T-cells, neutrophil granulocytes, basophils and adipocytes. There are many receptors capable of binding to CXCL8, but the most 


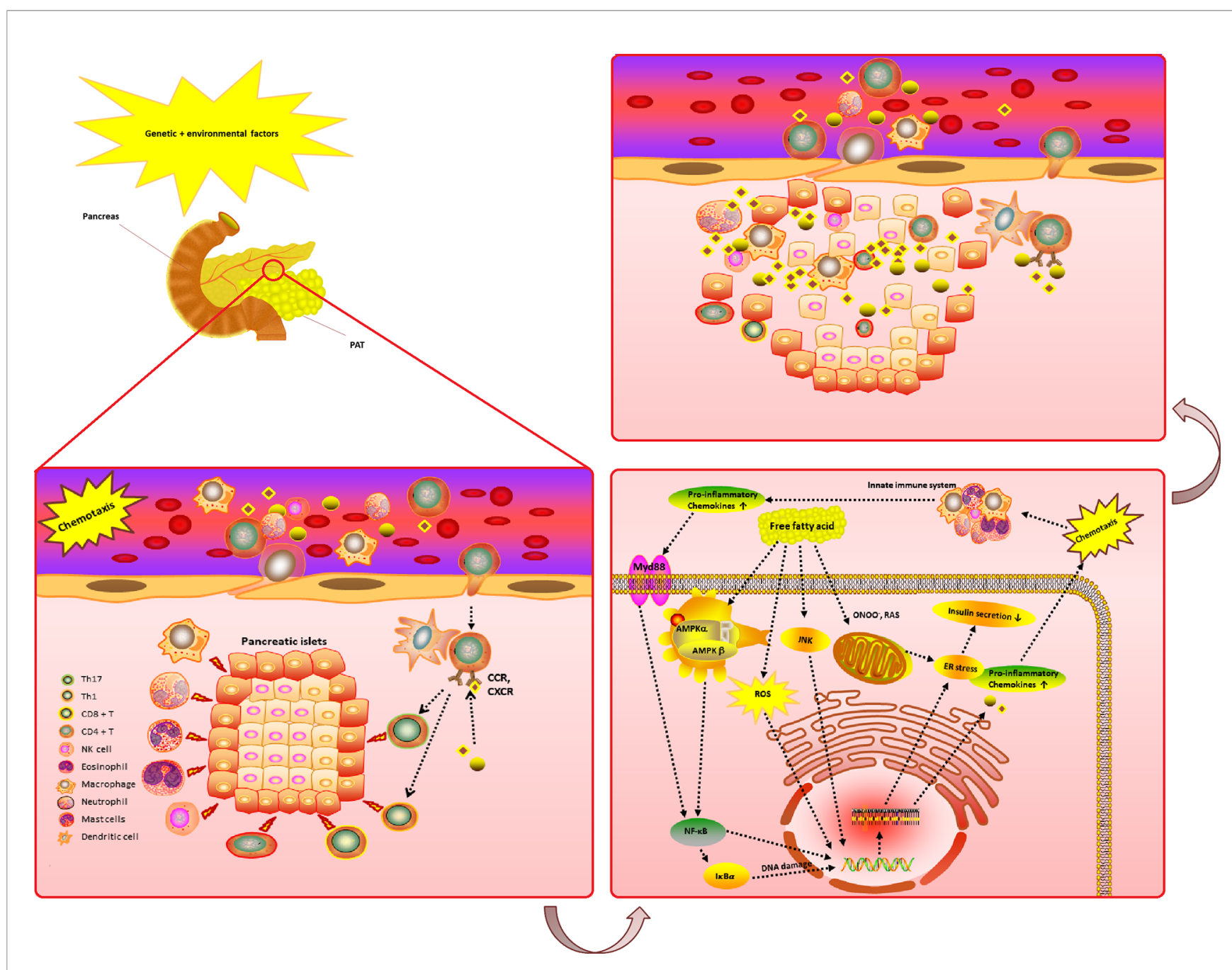

FIGURE 3 | The complicated chemokines and their receptors network in the microenvironment of T2DM. The chemokine system plays a variety of roles in the T2DM microenvironment. Pancreatic islets and PAT are exposed to an early damage by genetic or environmental factors and start to secrete numerous proinflammatory chemokines. The chemokines and their receptors can also cause a variety of immune cells to enter the pancreatic islets and PAT site to play the role of immune attack. Pro-inflammatory chemokines are bind to their receptors activating the NF- $\mathrm{kB} / \mathrm{kB} \alpha$ and AMPK activation pathway, which stimulates a proinflammatory condition. Free fatty acid may also activate inflammatory pathways and DNA damage. As a result of the Free fatty acid dysfunction, superoxide and subsequently hydrogen peroxide generation (which can combine with nitric oxide, an example of ONOO-, to create peroxynitrite, such as ROS/RNS) may occur due to compromised mitochondrial ETC and reducing ATP synthesis. All these processes impact ER stress, leading to a reduction in the ability to secrete insulin. Moreover, T2DM progression is characterized by progressive secretion of pro-inflammatory chemokines/cytokines caused by $\beta$ cell damage. Due to this process, various immune cell types (i.e., neutrophils, macrophages, NK cell, dendritic cell and specifically $T$ cells) are recruited in the pancreatic tissue. These immune cells further release more innate inflammatory cytokines, which contribute to a rapid increase $\beta$ cell death. T2DM, Type 2 diabetes mellitus; ROS, reactive oxygen species; RNS, reactive nitrogen species; NF-kB/lkB $\alpha$, nuclear factor-kappaB; ATP, adenosine triphosphate; PAT, peri-pancreatic adipose tissue; CCR, CC chemokines receptor; CXCR, CXC chemokines receptor; ETC, electron transport chain; AMPK, Adenosine 5-monophosphate activated protein-kinase; ER, endoplasmic reticulum; Protein kinase B (AKT); ONOO-, peroxynitrite; GLUT, glucose transporters; NK, Natural killer; Tregs, Regulatory T cells. (Drawn by AK.).

affinity to CXCL8 are receptors CXCR1 and CXCR2 (144). Clinical studies have shown that CXCL8 secreted by adipocytes may be related to complications, such as T2DM, which are related to the excess accumulation of intra-abdominal fat (145). Increasing evidence suggests that the intra-abdominal fat accumulation is closely related to decreased insulin sensitivity and increased T2DM pathophysiology $(145,146)$. These findings concur with the result of this study that T2DM patients have higher concentrations of CXCL8. Thus, CXCL8 may mediate the down regulation of adiponectin in obesity. Adiponectin can prevent the impairment of insulin signaling; hence CXCL8 may play a crucial and causal role in obesity-linked IR and T2DM (6).

Furthermore, as a member of the CXC chemokine family, CXCL10 is secreted by various cell types, such as monocytes, endothelial cells and fibroblasts. In this study, T2DM patients have been shown to have higher concentrations of CXCL10. This is possible because CXCL10 functions via chemokine receptor CXCR3 and toll-likereceptor 4 (TLR4) $(97,147)$. In addition, 
CXCL10 has been attributed to several roles, such as activating T-lymphocytes and monocytes/macrophages. Also, clinical studies have shown that the concentrations of CXCL10 secreted by patients with T2DM are higher than in the control group (97). Therefore, there is a hypothesis that the interferon gamma-inducible CXCL10 plays an important role in triggering $\beta$ cell destruction. Also, CXCL10 can impair insulin secretion and decrease $\beta$ cell viability. The specific mechanism may be that the CXCL10 induced $\beta$ cells can sustain the activation of protein kinase B (Akt), c-Jun N-terminal kinase (JNK), and cleavage of p21-activated protein kinase 2 (PAK-2); hence switching Akt signals from proliferation to apoptosis. These effects were mediated by the TLR4 $(147,148)$.

As the only known member of the CX3C chemokine family, CX3CL1 has the chemoattractive activity for T cells, NK cells, and monocytes (149). Clinical studies have shown that plasma CX3CL1 is significantly reduced in the control group compared to patients with T2DM, which is consistent with our results (34). The CX3CL1 is known to mediate leukocyte chemotaxis, adhesion and survival, which causes chronic adipose inflammation, and is closely associated with T2DM. Specifically, CX3CL1 may play a key role in recruiting monocytes to adipose tissue, and then leads to systemic inflammation and IR (150). The influence of CX3CL1mediated mechanism of leukocyte chemotaxis and adhesion might be a way that leads to T2DM and adipocyte dysfunction. Additionally, studies have shown that high CX3CL1 levels can lead to depletion of functional reserves of $\beta$ cells and chronic hyperinsulinemia, while inhibition of CX3CL1/CX3CR1 system can regulate pancreatic islet $\beta$-cell function (149). For example, Rosiglitazone inhibits CX3CL1 expression and CX3CL1/ CX3CR1 signaling by activating peroxisome proliferatoractivated receptor $\gamma$ (PPAR- $\gamma$ ), which can achieve the effect of treating IR and T2DM (151).

The subgroup results according to gender indicated that concentrations of chemokines were significantly higher in the T2DM female and male patients than in their respective control groups. However, no significant difference in these concentrations was observed between male PDM participants and controls. This result may suggest that gender differences are related to PDM. This is consistent with the results of some previous studies which suggested that gender hormones may play an important role in the pathogenesis of impaired fasting glucose (IFG) and impaired glucose tolerance (IGT) $(152,153)$. In general, IFG is more prevalent in males, whereas IGT is more prevalent in females $(152,154)$. Also, some studies on preclinical gender-related genetic differences have shown that chemokine gene polymorphisms are associated with gender $(155,156)$. Therefore, we conjecture that the high expression of chemokines in females in the early stage of diabetes may have an indirect effect on insulin resistance through pro-inflammatory effect, and may also play a direct role in impaired glucose tolerance affect by regulating metabolism, inflammation and insulin signaling pathways. Thus, gender-specific differences in the pathogenesis of PDM suggest consideration for personalized treatment of PDM according to gender.
Furthermore, subgroup analysis showed that, although the concentrations of chemokines were higher in both age groups with T2DM, the over 60 years old had a higher effect value (SMD) than the under 60 years. In fact, previous studies have shown that chemokines are deeply influenced by aging and age-related inflammation kinetics $(157,158)$. Moreover, these results suggest that the elderly cannot control excessive inflammatory state causing the pro-inflammatory cytokines (158-160). Therefore, we speculate that the high concentrations of chemokines with excessive inflammatory response in the elderly T2DM patients could be the response to the perturbations in their imbalanced immune microenvironment. How to improve this imbalanced immune microenvironment may be a novel issue that would indicate that therapies should target the immune microenvironment in the treatment of T2DM in the elderly (161).

In addition, subgroup analysis indicated that the T2DM patients had higher concentrations of chemokines than the controls, when chemokines were measured using the Luminex method and the ELISA method. However, no significant difference was observed between the PDM participants and the controls when the ELISA method was used. These results may suggest that there was a potential heterogeneity when chemokines detection method was ELISA, and Luminex method has higher sensitivity and specificity. Alternatively, in consisted with our results, some previous studies showed that the Luminex method is permit the rapid, simultaneous detection of multiple inflammatory factors and chemokines with high sensitivity and specificity $(162,163)$. Therefore, we recommend the use of Luminex method for chemokines detection in future studies.

This systematic review and meta-analysis has some strengths and limitations. For example, this study analyzed various chemokines using broad inclusion criteria. Therefore, the use of a comprehensive search strategy, with multiple variant names of chemokines when searching in the databases, is the main strength of this study. Besides, this study has helped to clarify the previously reported results on the association between chemokines and T2DM or PDM. Therefore, the findings might open up new perspectives in T2DM for early diagnosis, identification of novel biomarkers, and novel targets for pharmacological interventions.

However, the number of available studies on chemokines (e.g., CCL13, CCL15, CCL21, CXCL2 and CXCL6) is limited, which may lead to biased or imprecise results. Accordingly, future studies should pay more attention to the investigation of the role of chemokines in T2DM and PDM. Also, there was lack of the following information in the included original studies: BMI, blood pressure, smoking and drinking. Therefore, it was difficult to quantify various confounding factors at individual level. In this regard, confounding factors should be better reported in future studies. Further, the original data for this study came from cross-sectional or case-control studies, which may not make causal inference. Therefore, population-based cohort studies are needed in the future to establish causal relationships between chemokines and T2DM or PDM. 


\section{CONCLUSIONS}

This systematic review and meta-analysis suggests that the progression of PDM to T2DM may be associated with elevated concentrations of chemokines (CCL1, CCL2, CCL4, CCL5, CCL11, CXCL8, CXCL10 and CX3CL1). Understanding the complex interplay of chemokines and the progression of PDM to T2DM may facilitate the identification of potential targets in prevention, diagnosis, and treatment of T2DM. The value of these chemokines in clinical practice should be elucidated in further studies.

\section{DATA AVAILABILITY STATEMENT}

The original contributions presented in the study are included in the article/Supplementary Material, further inquiries can be directed to the corresponding author.

\section{AUTHOR CONTRIBUTIONS}

$\mathrm{XP}$ and AL contributed to the study design, while SW and AK contributed to the data collection. Statistical analyses and

\section{REFERENCES}

1. N. C. D. R. F. Collaboration. Worldwide trends in diabetes since 1980: a pooled analysis of 751 population-based studies with 4.4 million participants. Lancet (London England) (2016) 387(10027):1513-30. doi: 10.1016/S0140-6736(16)00618-8

2. Chatterjee S, Khunti K, Davies MJ. Type 2 diabetes. Lancet (2017) 389 (10085):2239-51. doi: 10.1016/s0140-6736(17)30058-2

3. Esser N, Paquot N, Scheen A. J. Anti-inflammatory agents to treat or prevent type 2 diabetes, metabolic syndrome and cardiovascular disease. Expert Opin Investig Drugs (2015) 24(3):283-307. doi: 10.1517/13543784. 2015.974804

4. Liu C, Feng X, Li Q, Wang Y, Li Q, Hua M. Adiponectin, TNF-alpha and inflammatory cytokines and risk of type 2 diabetes: A systematic review and meta-analysis. Cytokine (2016) 86:100-9. doi: 10.1016/j.cyto.2016.06.028

5. Rehman K, Akash MS. Mechanisms of inflammatory responses and development of insulin resistance: how are they interlinked? J BioMed Sci (2016) 23(1):87. doi: 10.1186/s12929-016-0303-y

6. Tretjakovs P, Jurka A, Bormane I, Mackevics V, Mikelsone I, Balode L, et al. Relation of inflammatory chemokines to insulin resistance and hypoadiponectinemia in coronary artery disease patients. Eur J Intern Med (2009) 20(7):712-7. doi: 10.1016/j.ejim.2009.08.004

7. Hosseini-Zijoud SM. Chemokines: Small molecules participate in diabetes. Iran J Allergy Asthma Immunol (2013) 12(1):S65.

8. Li JJ, Zhu $\mathrm{H}$, Shi $\mathrm{CH}$. Chemokines and diabetic retinopathy. Int J Ophthalmol (2011) 11(1):91-3. doi: 10.3969/j.issn.1672-5123.2011.01.030

9. Ochoa O, Torres FM, Shireman PK. Chemokines and diabetic wound healing. Vascular (2007) 15(6):350-5. doi: 10.2310/6670.2007.00056

10. Tabák AG, Herder C, Rathmann W, Brunner EJ, Kivimäki M. Prediabetes: a high-risk state for diabetes development. Lancet (2012) 379(9833):2279-90. doi: 10.1016/s0140-6736(12)60283-9

11. Wender-Ozegowska E, Michałowska-Wender G, Zawiejska A, Pietryga M, Brazert J, Wender M. Concentration of chemokines in peripheral blood in first trimester of diabetic pregnancy. Acta Obstetr Gynecol Scand (2018) 87 (1):14-9. doi: 10.1080/00016340701698724

12. Sindhu S, Akhter N, Arefanian H, Al-Roub AA, Ali S, Wilson A, et al. Increased circulatory levels of fractalkine (CX3CL1) are associated with interpretation of results were performed by $\mathrm{XP}$ and $\mathrm{AK}$, whereas XP and SW drafted the manuscript and edited the language. All authors contributed to the article and approved the submitted version.

\section{FUNDING}

The research is financially supported by Hunan Provincial Key Laboratory of Clinical Epidemiology and the Hunan Provincial Key Research and Development Program (2018SK2065), China.

\section{ACKNOWLEDGMENTS}

We are grateful to Central South University Library for the assistance during literature search.

\section{SUPPLEMENTARY MATERIAL}

The Supplementary Material for this article can be found online at: https://www.frontiersin.org/articles/10.3389/fimmu.2021. 622438/full\#supplementary-material

inflammatory chemokines and cytokines in individuals with type-2 diabetes. J Diabetes Metab Disord (2017) 16(1). doi: 10.1186/s40200017-0297-3

13. Moher D, Liberati A, Tetzlaff J, Altman DG. Preferred reporting items for systematic reviews and meta-analyses: the PRISMA statement. Bmj (2009) 339:b2535. doi: 10.1136/bmj.b2535

14. Pan X, Kaminga AC, Wen SW, Wu X, Acheampong K, Liu A. Dopamine and Dopamine Receptors in Alzheimer's Disease: A Systematic Review and Network Meta-Analysis. Front Aging Neurosci (2019) 11:175. doi: 10.3389/ fnagi.2019.00175

15. Pan X, Wu X, Kaminga AC, Wen SW, Liu A. Dehydroepiandrosterone and Dehydroepiandrosterone Sulfate in Alzheimer's Disease: A Systematic Review and Meta-Analysis. Front Aging Neurosci (2019) 1:61. doi: 10.3389/ fnagi.2019.00061

16. Pan X, Kaminga AC, Wen SW, Liu A. Catecholamines in Post-traumatic Stress Disorder: A Systematic Review and Meta-Analysis. Front Mol Neurosci (2018) 1:450. doi: 10.3389/fnmol.2018.00450

17. Pan X, Wang Z, Wu X, Wen SW, Liu A. Salivary cortisol in post-traumatic stress disorder: a systematic review and meta-analysis. BMC Psychiatry (2018) 18(1):324. doi: 10.1186/s12888-018-1910-9

18. Pan X, Kaminga AC, Wen SW, Acheampong K, Liu A. Omentin-1 in diabetes mellitus: A systematic review and meta-analysis. PloS One (2019) 14 (12):e0226292. doi: 10.1371/journal.pone.0226292

19. Pan X, Wen SW, Bestman PL, Kaminga AC, Acheampong K, Liu A. FetuinA in Metabolic syndrome: A systematic review and meta-analysis. PloS One (2020) 15(3):e0229776. doi: 10.1371/journal.pone.0229776

20. Pan X, Kaminga AC, Chen J, Luo M, Luo J. Fetuin-A and Fetuin-B in NonAlcoholic Fatty Liver Disease: A Meta-Analysis and Meta-Regression. Int $J$ Environ Res Public Health (2020) 17(8). doi: 10.3390/ijerph17082735

21. Higgins JP, Thompson SG, Deeks JJ, Altman DG. Measuring inconsistency in meta-analyses. Bmj (2003) 327(7414):557-60. doi: 10.1136/ bmj.327.7414.557

22. Pan X, Zhao L, Luo J, Li Y, Zhang L, Wu T, et al. Access to bike lanes and childhood obesity: A systematic review and meta-analysis. Obes Rev (2020). doi: $10.1111 /$ obr.13042

23. Higgins JP, Thompson SG. Quantifying heterogeneity in a meta-analysis. Stat Med (2002) 21(11):1539-58. doi: 10.1002/sim.1186 
24. Egger M, Davey Smith G, Schneider M, Minder C. Bias in meta-analysis detected by a simple, graphical test. Bmj (1997) 315(7109):629-34. doi: 10.1136/bmj.315.7109.629

25. Adela R, Reddy PNC, Ghosh TS, Aggarwal S, Yadav AK, Das B, et al. Serum protein signature of coronary artery disease in type 2 diabetes mellitus. J Transl Med (2019) 7(1):17. doi: 10.1186/s12967-018-1755-5

26. Afarideh M, Ghanbari P, Noshad S, Ghajar A, Nakhjavani M, Esteghamati A. Raised serum 25-hydroxyvitamin D levels in patients with active diabetic foot ulcers. Br J Nutr (2016) 115(11):1938-46. doi: 10.1017/S0007114516001094

27. Ahmed SF, Shabayek MI, Ghany MEA, El-Hefnawy MH, El-Mesallamy HO. Role of CTRP3, CTRP9 and MCP-1 for the evaluation of T2DM associated coronary artery disease in Egyptian postmenopausal females. PloS One (2018) 13(12). doi: 10.1371/journal.pone.0208038

28. Alicka M, Major P, Wysocki M, Marycz K. Adipose-Derived Mesenchymal Stem Cells Isolated from Patients with Type 2 Diabetes Show Reduced "Stemness" through an Altered Secretome Profile, Impaired Anti-Oxidative Protection, and Mitochondrial Dynamics Deterioration. J Clin Med (2019) 8 (6). doi: $10.3390 / \mathrm{jcm} 8060765$

29. Almeida-Pititto B, Ribeiro-Filho FF, Lotufo PA, Bensenor IM, Ferreira SR. Novel biomarkers of cardiometabolic risk are associated with plasma glucose within non-diabetic range. The Brazilian Longitudinal Study of Adult Health - ELSA-Brasil. Diabetes Res Clin Pract (2015) 109(1):110-6. doi: 10.1016/j.diabres.2015.04.021

30. Alvarado-Vazquez PA, Grosick RL, Moracho-Vilrriales C, Ward E, Threatt T, Romero-Sandoval EA. Cytokine production capabilities of human primary monocyte-derived macrophages from patients with diabetes mellitus type 2 with and without diabetic peripheral neuropathy. J Pain Res (2019) 12:69-81. doi: 10.2147/JPR.S186372

31. Aravindhan V, Kevinkumar V, Dhamodharan U, Viswanathan V. Serum levels of chemokines IP-10, IL-8 and SDF-1 serve as good biomarkers for diabetes-tuberculosis nexus. J Diabetes Its Complicat (2018) 32(9):857-62. doi: 10.1016/j.jdiacomp.2018.07.001

32. Bala M, Kopp A, Wurm S, Büchler C, Schölmerich J, Schäffler A. Type 2 diabetes and lipoprotein metabolism affect LPS-induced cytokine and chemokine release in primary human monocytes. Exp Clin Endocrinol Diabetes 119(6):370-6. doi: 10.1055/s-0030-1268413

33. Baldane S, Kendir IC, Kirac CO, Ipekci S, Tekin G, Unlu A, et al. Effects Of Glucose Ingestion On Serum Fractalkine Levels In Healthy Subjects And Newly Diagnosed Type 2 Diabetic Patients. J Med Biochem 37(3):373-8. doi: 10.1515/jomb-2017-0070

34. Baldane S, Ipekci SH, Ekin A, Abusoglu S, Unlu A, Kebapcilar L. Evaluation of fractalkine (FKN) and secreted frizzled-related protein 4 (SFRP-4) serum levels in patients with prediabetes and type 2 diabetes. Bratislava Med J-Bratislavske Lekarske Listy (2018) 119(2):112-5. doi: 10.4149/bll_2018_021

35. Barchetta I, Cimini FA, Capoccia D, De Gioannis R, Porzia A, Mainiero F, et al. WISP1 Is a Marker of Systemic and Adipose Tissue Inflammation in Dysmetabolic Subjects With or Without Type 2 Diabetes. J Endocr Soc (2017) 1(6):660-70. doi: 10.1210/js.2017-00108

36. Cataño Cañizales YG, Uresti Rivera EE, García Jacobo RE, Portales Perez DP, Yadira B, Rodriguez Rivera JG, et al. Increased Levels of AIM2 and Circulating Mitochondrial DNA in Type 2 Diabetes. Iran J Immunol (2018) 15(2):142-55

37. Capone F, Guerriero E, Colonna G, Maio P, Mangia A, Marfella R, et al. The Cytokinome Profile in Patients with Hepatocellular Carcinoma and Type 2 Diabetes. PloS One (2015) 10(7):e0134594. doi: 10.1371/ journal.pone.0134594

38. Cha JJ, Hyun YY, Jee YH, Lee MJ, Han KH, Kang YS, et al. Plasma leptin concentrations are greater in type II diabetic patients and stimulate monocyte chemotactic peptide-1 synthesis via the mitogen-activated protein kinase/extracellular signal-regulated kinase pathway. Kidney Res Clin Pract (2012) 31(3):177-85. doi: 10.1016/j.krcp.2012.06.004

39. Chang C-C, Wu C-L, Su W-W, Shih K-L, Tarng D-C, Chou C-T, et al. Interferon gamma-induced protein 10 is associated with insulin resistance and incident diabetes in patients with nonalcoholic fatty liver disease. Sci Rep (2015) 5. doi: 10.1038/srep10096

40. Chao PC, Huang CN, Hsu CC, Yin MC, Guo YR. Association of dietary AGEs with circulating AGEs, glycated LDL, IL- $1 \alpha$ and MCP-1 levels in type 2 diabetic patients. Eur J Nutr (2017) 49(7):429-34. doi: 10.1007/s00394-0100101-3

41. Chen H, Zhang X, Liao N, Wen F. Assessment of biomarkers using multiplex assays in aqueous humor of patients with diabetic retinopathy. BMC Ophthalmol (2017) 17(1):176. doi: 10.1186/s12886-017-0572-6

42. Cheng M, Li BY, Li XL, Wang Q, Zhang JH, Jing XJ, et al. Correlation between serum lactadherin and pulse wave velocity and cardiovascular risk factors in elderly patients with type 2 diabetes mellitus. Diabetes Res Clin Pract (2012) 95(1):125-31. doi: 10.1016/ j.diabres.2011.09.030

43. Cheung CMG, Vania M, Ang M, Chee SP, Li J. Comparison of aqueous humor cytokine and chemokine levels in diabetic patients with and without retinopathy. Mol Vision (2012) 18(87-88):830-7.

44. Cimini FA, Barchetta I, Porzia A, Mainiero F, Costantino C, Bertoccini L, et al. Circulating IL-8 levels are increased in patients with type 2 diabetes and associated with worse inflammatory and cardiometabolic profile. Acta Diabetol (2017) 54(10):961-7. doi: 10.1007/s00592-017-1039-1

45. Cimini FA, D’Eliseo D, Barchetta I, Bertoccini L, Velotti F, Cavallo MG. Increased circulating granzyme B in type 2 diabetes patients with low-grade systemic inflammation. Cytokine (2019) 115:104-8. doi: 10.1016/ j.cyto.2018.11.019

46. Danielsson P, Truedsson L, Eriksson KF, Norgren L. Inflammatory markers and IL-6 polymorphism in peripheral arterial disease with and without diabetes mellitus. Vasc Med (2005) 10(3):191-8. doi: 10.1191/ 1358863x05vm617oa

47. Davì G, Tuttolomondo A, Santilli F, Basili S, Ferrante E, Di Raimondo D, et al. CD40 ligand and MCP-1 as predictors of cardiovascular events in diabetic patients with stroke. J Atheroscl Thromb (2009) 16(6):707-13. doi: $10.5551 /$ jat. 1537

48. Desfaits AC, Serri O, Renier G. Normalization of plasma lipid peroxides, monocyte adhesion, and tumor necrosis factor-alpha production in NIDDM patients after gliclazide treatment. Diabetes Care (1998) 21(4):487-93 doi: $10.2337 /$ diacare.21.4.487

49. Degirmenci I, Ozbayer C, Kebapci MN, Kurt H, Colak E, Gunes HV Common variants of genes encoding TLR4 and TLR4 pathway members TIRAP and IRAK1 are effective on MCP1, IL6, IL1beta, and TNFalpha levels in type 2 diabetes and insulin resistance. Inflammation Res (2019) 68 (9):801-14. doi: 10.1007/s00011-019-01263-7

50. Derakhshan R, Arababadi MK, Ahmadi Z, Karimabad MN, Salehabadi VA, Abedinzadeh $\mathrm{M}$, et al. Increased circulating levels of SDF-1 (CXCL12) in type 2 diabetic patients are correlated to disease state but are unrelated to polymorphism of the SDF-1 $\beta$ gene in the Iranian population. Inflammation (2012) 35(3):900-4. doi: 10.1007/s10753-011-9391-8

51. El-Mesallamy HO, Hamdy NM, Salman TM, Ibrahim SM. Adiponectin and sE-selectin concentrations in relation to inflammation in obese type 2 diabetic patients with coronary heart disease. Angiology (2012) 63(2):96102. doi: $10.1177 / 0003319711408587$

52. Feng S, Yu H, Yu Y, Geng Y, Li D, Yang C, et al. Levels of inflammatory cytokines IL-1 $\beta$, IL-6, IL-8, IL-17A, and TNF- $\alpha$ in aqueous humour of patients with diabetic retinopathy. J Diabetes Res (2018) (2018). doi: $10.1155 / 2018 / 8546423$

53. Funatsu H, Noma H, Mimura T, Eguchi S, Hori S. Association of vitreous inflammatory factors with diabetic macular edema. Ophthalmology (2009) 116(1):73-9. doi: 10.1016/j.ophtha.2008.09.037

54. Geerlings SE, Brouwer EC, Van Kessel KC, Gaastra W, Stolk RP, Hoepelman AI. Cytokine secretion is impaired in women with diabetes mellitus. Eur J Clin Invest (2000) 30(11):995-1001. doi: 10.1046/j.13652362.2000.00745.x

55. Giulietti A, van Etten E, Overbergh L, Stoffels K, Bouillon R, Mathieu C. Monocytes from type 2 diabetic patients have a pro-inflammatory profile. 1,25-Dihydroxyvitamin D(3) works as anti-inflammatory. Diabetes Res Clin Pract (2007) 77(1):47-57. doi: 10.1016/j.diabres.2006.10.007

56. Gokulakrishnan K, Amutha A, Ranjani H, Bibin SY, Balakumar M, Pandey GK, et al. Relationship of Adipokines and Proinflammatory Cytokines among Asian Indians with Obesity and Youth Onset Type 2 Diabetes. Endocr Pract (2015) 21(10):1143-51. doi: 10.4158/EP15741.OR

57. Gomez JM, Vila R, Catalina P, Soler J, Badimon L, Sahun M. The markers of inflammation and endothelial dysfunction in correlation with glycated 
haemoglobin are present in type 2 diabetes mellitus patients but not in their relatives. Glycoconj J (2008) 25(6):573-9. doi: 10.1007/s10719-008-9118-8

58. Gong F, Wu J, Zhou P, Zhang M, Liu J, Liu Y, et al. Interleukin-22 Might Act as a Double-Edged Sword in Type 2 Diabetes and Coronary Artery Disease. Mediators Inflammation (2016) 2016:8254797. doi: 10.1155/2016/8254797

59. Hamid S, Gul A, Hamid Q. Relationship of cytokines and AGE products in diabetic and non-diabetic patients with cataract. Int J Health Sci (Qassim) (2016) 10(4):507-15. doi: 10.12816/0048891

60. Hara Cde C, Franca EL, Fagundes DL, de Queiroz AA, Rudge MV, HonorioFranca AC, et al. Characterization of Natural Killer Cells and Cytokines in Maternal Placenta and Fetus of Diabetic Mothers. J Immunol Res (2016) 2016:7154524. doi: 10.1155/2016/7154524

61. He L, Wong CK, Cheung KK, Yau HC, Fu A, Zhao HL, et al. Antiinflammatory effects of exendin-4, a glucagon-like peptide-1 analog, on human peripheral lymphocytes in patients with type 2 diabetes. J Diabetes Investig (2013) 4(4):382-92. doi: 10.1111/jdi.12063

62. Herder C, Müller-Scholze S, Rating P, Koenig W, Thorand B, Haastert B, et al. Systemic monocyte chemoattractant protein-1 concentrations are independent of type 2 diabetes or parameters of obesity: results from the Cooperative Health Research in the Region of Augsburg Survey S4 (KORA S4). Eur J Endocrinol (2006) 154(2):311-7. doi: 10.1530/eje.1.02090

63. Herder C, Illig T, Baumert J, Müller M, Klopp N, Khuseyinova N, et al. RANTES/CCL5 gene polymorphisms, serum concentrations, and incident type diabetes: Results from the MONICA/KORA Augsburg case-cohort study, 1984-2002. Eur J Endocrinol 158(5):R1-5. doi: 10.1530/EJE-07-0686

64. Hernández C, Segura RM, Fonollosa A, Carrasco E, Francisco G, Simó R. Interleukin-8, monocyte chemoattractant protein- 1 and IL-10 in the vitreous fluid of patients with proliferative diabetic retinopathy. Diabetes Med (2005) 22(6):719-22. doi: 10.1111/j.1464-5491.2005.01538.x

65. Hirsch FF, Pareja JC, Geloneze SR, Chaim E, Cazzo E, Geloneze B. Comparison of metabolic effects of surgical-induced massive weight loss in patients with long-term remission versus non-remission of type 2 diabetes. Obes Surg (2012) 22(6):910-7. doi: 10.1007/s11695-012-0589-0

66. Hu YY, Ye SD, Zhao LL, Zheng M, Wu FZ, Chen Y. Hydrochloride pioglitazone decreases urinary cytokines excretion in type 2 diabetes. Clin Endocrinol (Oxf) (2010) 73(6):739-43. doi: 10.1111/j.1365-2265.2010.03878.x

67. Huang G, Mo X, Li M, Xiang Y, Li X, Luo S, et al. Autoantibodies to CCL3 are of low sensitivity and specificity for the diagnosis of type 1 diabetes. Acta Diabetol (2012) 49(5):395-9. doi: 10.1007/s00592-012-0380-7

68. Inayat H, Azim MK, Baloch AA. Analysis of Inflammatory Gene Expression Profile of Peripheral Blood Leukocytes in Type 2 Diabetes. Immunol Invest (2019) 48(6):618-31. doi: 10.1080/08820139.2019.1586917

69. Kalninova J, Jakus V, Glejtkova M, Kuracka L, Sandorova E. Impact of glycemic control on advanced glycation and inflammation in overweight and obese patients with type 2 diabetes mellitus. Bratisl Lek Listy (2014) 115 (8):457-68. doi: 10.4149/bll_2014_089

70. Kang YS, Song HK, Lee MH, Ko GJ, Cha DR. Plasma concentration of visfatin is a new surrogate marker of systemic inflammation in type 2 diabetic patients. Diabetes Res Clin Pract (2010) 89(2):141-9. doi: 10.1016/ j.diabres.2010.03.020

71. Kou H, Deng J, Gao D, Song A, Han Z, Wei J, et al. Relationship among adiponectin, insulin resistance and atherosclerosis in non-diabetic hypertensive patients and healthy adults. Clin Exp Hypertens (2018) 40 (7):656-63. doi: 10.1080/10641963.2018.1425414

72. Pavan Kumar P, Radhika G, Rao GV, Pradeep R, Subramanyam C, Talukdar R, et al. Interferon $\gamma$ and glycemic status in diabetes associated with chronic pancreatitis. Pancreatology (2012) 12(1):65-70. doi: 10.1016/j.pan.2011.12.005

73. Kumar NP, Sridhar R, Banurekha VV, Jawahar MS, Fay MP, Nutman TB, et al. Type 2 diabetes mellitus coincident with pulmonary tuberculosis is associated with heightened systemic type 1, type 17, and other proinflammatory cytokines. Ann Am Thorac Soc (2013) 10(5):441-9. doi: 10.1513/AnnalsATS.201305-112OC

74. Landers-Ramos RQ, Blumenthal JB, Prior SJ. Serum IL-6 and sIL-6R in type 2 diabetes contribute to impaired capillary-like network formation. J Appl Physiol (1985) (2019) 127(2):385-92. doi: 10.1152/japplphysiol.00002.2019

75. Lareyre F, Moratal C, Chikande J, Jean-Baptiste E, Hassen-Khodja R, Neels J, et al. Investigation of Plasma Inflammatory Profile in Diabetic Patients With
Abdominal Aortic Aneurysm: A Pilot Study. Vasc Endovasc Surg (2018) 52 (8):597-601. doi: 10.1177/1538574418784717

76. Li C, Kang D, Sun X, Liu Y, Wang J, Gao P. The Effect of C-X-C Motif Chemokine 13 on Hepatocellular Carcinoma Associates with Wnt Signaling. BioMed Res Int (2015) 2015:345413. doi: 10.1155/2015/345413

77. Liu S, Huang J, Yu F, Wang J, Zhang Q, Qu S, et al. The expression of chemerin and chemerin receptor in MCD induced NAFLD rat. Diabetes (2011) 60:A686. doi: 10.2337/db11-2585-2680

78. Liu T, Xue R, Dong L, Wu H, Zhang D, Shen X. Rapid determination of serological cytokine biomarkers for hepatitis B virus-related hepatocellular carcinoma using antibody microarrays. Acta Biochim Biophys Sin (Shanghai) (2011) 43(1):45-51. doi: 10.1093/abbs/gmq111

79. Liuni FM, Rugiero C, Feola M, Rao C, Pistillo P, Terracciano C, et al. Impaired healing of fragility fractures in type 2 diabetes: clinical and radiographic assessments and serum cytokine levels. Aging Clin Exp Res (2015) 27(Suppl 1):S37-44. doi: 10.1007/s40520-015-0422-4

80. Lu P, Ji X, Wan J, Xu H. Activity of Group 2 Innate Lymphoid Cells is Associated with Chronic Inflammation and Dysregulated Metabolic Homoeostasis in Type 2 Diabetic Nephropathy. Scand J Immunol (2018) 87(2):99-107. doi: 10.1111/sji.12637

81. Maegdefessel L, Schlitt A, Pippig S, Schwaab B, Fingscheidt K, Raaz U, et al. Patients with insulin-dependent diabetes or coronary heart disease following rehabilitation express serum fractalkine levels similar to those in healthy control subjects. Vasc Health Risk Manage (2009) 5:849-57. doi: 10.2147/ VHRM.S6829

82. Maier R, Weger M, Haller-Schober EM, El-Shabrawi Y, Wedrich A, Theisl A, et al. Multiplex bead analysis of vitreous and serum concentrations of inflammatory and proangiogenic factors in diabetic patients. Mol Vis (2008) 14:637-43.

83. Mangialardi G, Ferland-McCollough D, Maselli D, Santopaolo M, Cordaro A, Spinetti G, et al. Bone marrow pericyte dysfunction in individuals with type 2 diabetes. Diabetologia (2019) 62(7):1275-90. doi: 10.1007/s00125-019-4865-6

84. McCarthy CP, Shrestha S, Ibrahim N, van Kimmenade RRJ, Gaggin HK, Mukai R, et al. Performance of a clinical/proteomic panel to predict obstructive peripheral artery disease in patients with and without diabetes mellitus. Open Heart (2019) 6(1):e000955. doi: 10.1136/openhrt-2018000955

85. Mesia R, Gholami F, Huang H, Clare-Salzler M, Aukhil I, Wallet SM, et al. Systemic inflammatory responses in patients with type 2 diabetes with chronic periodontitis. BMJ Open Diabetes Res Care (2016) 4(1):e000260. doi: 10.1136/bmjdrc-2016-000260

86. Mine S, Okada Y, Tanikawa T, Kawahara C, Tabata T, Tanaka Y. Increased expression levels of monocyte CCR2 and monocyte chemoattractant protein-1 in patients with diabetes mellitus. Biochem Biophys Res Commun (2006) 344(3):780-5. doi: 10.1016/j.bbrc.2006.03.197

87. Mohamed HG, Idris SB, Ahmed MF, Astrom AN, Mustafa K, Ibrahim SO, et al. Influence of type 2 diabetes on local production of inflammatory molecules in adults with and without chronic periodontitis: a cross-sectional study. BMC Oral Health (2015) 15:86. doi: 10.1186/s12903-015-0073-z

88. Murase H, Suzuki E, Tajima Y, Hayashi K, Nakamura T, Noritake N, et al. Associations of plasma von Willebrand factor ristocetin cofactor activity and 5-hydroxyindole acetic acid concentrations with blood flow in lower-leg arteries in Japanese type 2 diabetic patients with normal ankle-brachial index. J Diabetes Complicat (2012) 26(2):113-7. doi: 10.1016/j.jdiacomp. 2012.02.003

89. Nomura S, Shouzu A, Omoto S, Nishikawa M, Iwasaka T. Benidipine improves oxidized LDL-dependent monocyte and endothelial dysfunction in hypertensive patients with type 2 diabetes mellitus. J Hum Hypertens (2005) 19(7):551-7. doi: 10.1038/sj.jhh.1001863

90. Omoto S, Taniura T, Nishizawa T, Tamaki T, Shouzu A, Nomura S. Anti-atherosclerotic effects of sitagliptin in patients with type 2 diabetes mellitus. Diabetes Metab Syndr Obes (2015) 8:339-45. doi: 10.2147/ DMSO.S84545

91. Papatheodorou K, Papanas N, Papazoglou D, Gioka T, Antonoglou C, Glaros D, et al. Monocyte chemoattractant protein 1 is correlated with glycemic control and peripheral arterial disease in type 2 diabetic patients with metabolic syndrome. Angiology (2013) 64(3):223-9. doi: 10.1177/ 0003319712440143 
92. Pham MN, Hawa MI, Roden M, Schernthaner G, Pozzilli P, Buzzetti R, et al. Increased serum concentrations of adhesion molecules but not of chemokines in patients with Type2 diabetes compared with patients with Typel diabetes and latent autoimmune diabetes in adult age: Action LADA5. Diabetic Med (2012) 29(4):470-8. doi: 10.1111/j.1464-5491.2011.03546.x

93. Porta M, Amione C, Barutta F, Fornengo P, Merlo S, Gruden G, et al. The co-activator-associated arginine methyltransferase 1 (CARM1) gene is overexpressed in type 2 diabetes. Endocrine (2019) 63(2):284-92. doi: $10.1007 / \mathrm{s} 12020-018-1740-\mathrm{z}$

94. Prechel M, Hudec S, Lowden E, Escalante V, Emanuele N, Emanuele M, et al. Profiling Heparin-Induced Thrombocytopenia (HIT) Antibodies in Hospitalized Patients With and Without Diabetes. Clin Appl Thromb Hemost (2018) 24(9_suppl):294S-300S. doi: 10.1177/1076029618808915

95. Pushpanathan P, Srikanth P, Seshadri KG, Selvarajan S, Pitani RS, Kumar TD, et al. Gut Microbiota in Type 2 Diabetes Individuals and Correlation with Monocyte Chemoattractant Protein1 and Interferon Gamma from Patients Attending a Tertiary Care Centre in Chennai, India. Indian J Endocrinol Metab (2016) 20(4):523-30. doi: 10.4103/2230-8210.183474

96. Ruotsalainen E, Stancakova A, Vauhkonen I, Salmenniemi U, Pihlajamaki J, Punnonen K, et al. Changes in cytokine levels during acute hyperinsulinemia in offspring of type 2 diabetic subjects. Atherosclerosis (2010) 210(2):536-41. doi: 10.1016/j.atherosclerosis.2009.11.036

97. Sajadi SMA, Khoramdelazad H, Hassanshahi G, Rafatpanah H, Hosseini J, Mahmoodi M, et al. Plasma Levels of CXCL1 (GRO-alpha) and CXCL10 (IP10) are Elevated in Type 2 Diabetic Patients: Evidence for the Involvement of Inflammation and Angiogenesis/Angiostasis in this Disease State. Clin Lab (2013) 59(1-2):133-7. doi: 10.7754/Clin.Lab.2012.120225

98. Samaras K, Botelho NK, Chisholm DJ, Lord RV. Subcutaneous and visceral adipose tissue gene expression of serum adipokines that predict type 2 diabetes. Obes (Silver Spring) (2010) 18(5):884-9. doi: 10.1038/oby.2009.443

99. Sathishkumar C, Prabu P, Balakumar M, Lenin R, Prabhu D, Anjana RM, et al. Augmentation of histone deacetylase 3 (HDAC3) epigenetic signature at the interface of proinflammation and insulin resistance in patients with type 2 diabetes. Clin Epigenet (2016) 8:125. doi: 10.1186/s13148-016-0293-3

100. Saukkonen T, Mutt SJ, Jokelainen J, Saukkonen AM, Raza GS, Karhu T, et al. Adipokines and inflammatory markers in elderly subjects with high risk of type 2 diabetes and cardiovascular disease. Sci Rep (2018) 8(1):12816. doi: 10.1038/s41598-018-31144-8

101. Shah R, Hinkle CC, Ferguson JF, Mehta NN, Li M, Qu L, et al. Fractalkine is a novel human adipochemokine associated with type 2 diabetes. Diabetes (2011) 60(5):1512-8. doi: 10.2337/db10-0956

102. Sindhu S, Akhter N, Shenouda S, Wilson A, Ahmad R. Plasma fetuin-A/ alpha 2-HS-glycoprotein correlates negatively with inflammatory cytokines, chemokines and activation biomarkers in individuals with type- 2 diabetes. BMC Immunol (2016). doi: 10.1186/s12865-016-0171-y

103. Sozer V, Himmetoglu S, Korkmaz GG, Kaya S, Aydin S, Yumuk V, et al. Paraoxonase, oxidized low density lipoprotein, monocyte chemoattractant protein-1 and adhesion molecules are associated with macrovascular complications in patients with type 2 diabetes mellitus. Minerva Med (2014) 105(3):237-44.

104. Tavangar A, Khozeimeh F, Ghoreishian F, Boroujeni MA. Serum level of Interleukin-8 in subjects with diabetes, diabetes plus oral lichen planus, and oral lichen planus: A biochemical study. Dent Res J (Isfahan) (2016) 13 (5):413-8. doi: 10.4103/1735-3327.192277

105. Tavangar A, Ghalayani P, Boroujeni MA, Ghoreishian FS. Salivary levels of interleukin-8 in oral lichen planus and diabetic patients: A biochemical study. Dent Res J (Isfahan) (2017) 14(3):209-14. doi: 10.4103/17353327.208771

106. Toan NL, Van Hoan N, Cuong DV, Dung NV, Dung PT, Hang NT, et al. Adipose tissue-derived cytokines and their correlations with clinical characteristics in Vietnamese patients with type 2 diabetes mellitus. Diabetol Metab Syndr (2018) 10:41. doi: 10.1186/s13098-018-0343-4

107. Tokarz A, Drozdz AE, Szuzcik I, Stzpiez E. Interplay of RANTES chemokine and CCR5+ bearing microvesicles in diabetic retinopathy. J Extracell Vesicles (2017) 6:119. doi: 10.1080/20013078.2017.1310414

108. Tvarijonaviciute A, Castillo C, Ceron JJ, Martinez-Subiela S, Tecles F, LopezJornet P. Leptin and NGF in saliva of patients with diabetes mellitus type 2: A pilot study. J Oral Pathol Med (2017) 46(9):853-5. doi: 10.1111/jop.12587
109. Umapathy D, Dornadula S, Krishnamoorthy E, Mariappanadar V, Viswanathan V, Ramkumar KM. YKL-40: A biomarker for early nephropathy in type 2 diabetic patients and its association with inflammatory cytokines. Immunobiology (2018) 223(11):718-27. doi: 10.1016/j.imbio.2018.07.020

110. Wada T, Furuichi K, Sakai N, Iwata Y, Yoshimoto K, Shimizu M, et al. Upregulation of monocyte chemoattractant protein-1 in tubulointerstitial lesions of human diabetic nephropathy. Kidney Int (2000) 58(4):1492-9. doi: 10.1046/j.1523-1755.2000.00311.x

111. Wang X, Li J, Wang Z, Deng A. Wound exudate CXCL6: a potential biomarker for wound healing of diabetic foot ulcers. Biomarkers Med 13 (3):167-74. doi: 10.2217/bmm-2018-0339

112. Wei J, Tang Q, Liu L, Bin J. Combination of peroxisome proliferatoractivated receptor alpha/gamma agonists may benefit type 2 diabetes patients with coronary artery disease through inhibition of inflammatory cytokine secretion. Exp Ther Med 5(3):783-8. doi: 10.3892/etm.2013.891

113. Wu C, Wang Q, Lv C, Qin N, Lei S, Yuan Q, et al. The changes of serum sKlotho and NGAL levels and their correlation in type 2 diabetes mellitus patients with different stages of urinary albumin. Diabetes Res Clin Pract (2019) 106(2):343-50. doi: 10.1016/j.diabres.2014.08.026

114. Xu J, Liao YF, Zhou WP, Ming HL, Wang QH. The MCP-1 Gene A-2518G Polymorphism Confers an Increased Risk of Vascular Complications in Type 2 Diabetes Mellitus Patients. Genet Testing Mol Biomarkers (2013) 19 (8):411-7. doi: 10.1089/gtmb.2014.0325

115. Yadav R, Hama S, Liu Y, Siahmansur T, Schofield J, Syed AA, et al. Effect of Roux-en-Y Bariatric Surgery on Lipoproteins, Insulin Resistance, and Systemic and Vascular Inflammation in Obesity and Diabetes. Front Immunol (2014) 8:1512. doi: 10.3389/fimmu.2017.01512

116. Yang M, Shen Z, Chen D, Gan H, Shen Q, Yang B, et al. Effects of 1,25-(OH) (2)D (3) on the expressions of vitamin D receptor, STAT5 and cytoskeletal rearrangement in human monocytes incubated with sera from type 2 diabetes patients and diabetic nephropathy patients with uremia. Inflammation Res (2012) 61(5):511-20. doi: 10.1007/s00011-012-0441-y

117. Yi B, Hu X, Zhang H, Huang J, Liu J, Hu J, et al. Nuclear NF-kappaB p65 in peripheral blood mononuclear cells correlates with urinary MCP-1, RANTES and the severity of type 2 diabetic nephropathy. PloS One (2014) 9(6):e99633. doi: 10.1371/journal.pone.0099633

118. Zeng Y, Cao D, Yu H, Hu Y, He M, Yang D, et al. Comprehensive analysis of vitreous humor chemokines in type 2 diabetic patients with and without diabetic retinopathy. Acta Diabetol (2019) 56(7):797-805. doi: 10.1007/ s00592-019-01317-6

119. Zhang J, Zhang Z, Ding Y, Xu P, Wang T, Xu W, et al. Adipose Tissues Characteristics of Normal, Obesity, and Type 2 Diabetes in Uygurs Population. J Diabetes Res (2015) 2015:905042. doi: 10.1155/2015/905042

120. Zhou F, Wang J, Wang K, Zhu X, Pang R, Li X, et al. Serum CXCL16 as a Novel Biomarker of Coronary Artery Disease in Type 2 Diabetes Mellitus: a Pilot Study. Ann Clin Lab Sci (2016) 46(2):184-9.

121. Antonelli A, Ferri C, Ferrari SM, Frascerra S, Ruffilli I, Caponi L, et al. High levels of circulating chemokine (C-X-C motif) ligand 11 are associated with euthyroid or subclinically hypothyroid autoimmune thyroiditis and with chemokine (C-X-C motif) ligand 10. J Interferon Cytokine Res (2012) 32 (2):74-80. doi: $10.1089 /$ jir.2011.0051

122. Antonelli A, Ferrari SM, Frascerra S, Di Domenicantonio A, Nicolini A, Ferrari P, et al. Increase of circulating CXCL9 and CXCL11 associated with euthyroid or subclinically hypothyroid autoimmune thyroiditis. J Clin Endocrinol Metab (2011) 96(6):1859-63. doi: 10.1210/jc.2010-2905

123. Antonelli A, Ferrari SM, Frascerra S, Ruffilli I, Gelmini S, Minuto M, et al. Peroxisome proliferator-activated receptor- $\alpha$ agonists modulate CXCL9 and CXCL11 chemokines in Graves' ophthalmopathy fibroblasts and preadipocytes. Mol Cell Endocrinol (2012) 349(2):255-61. doi: 10.1016/ j.mce.2011.11.001

124. Antonelli A, Ferrari SM, Corrado A, Ferrannini E, Fallahi P. Increase of interferon- $\gamma$ inducible CXCL9 and CXCL11 serum levels in patients with active Graves' disease and modulation by methimazole therapy. Thyroid (2013) 23(11):1461-9. doi: 10.1089/thy.2012.0485

125. Fallahi P, Ferrari SM, Ragusa F, Ruffilli I, Elia G, Paparo SR, et al. Th1 Chemokines in Autoimmune Endocrine Disorders. J Clin Endocrinol Metab (2000) 105(4). doi: 10.1210/clinem/dgz289 
126. Antonelli A, Ferrari SM, Giuggioli D, Ferrannini E, Ferri C, Fallahi P. Chemokine (C-X-C motif) ligand (CXCL) 10 in autoimmune diseases. Autoimmun Rev (2014) 13(3):272-80. doi: 10.1016/j.autrev.2013.10.010

127. Fallahi P, Ferrari SM, Corrado A, Giuggioli D, Ferri C, Antonelli A. Targeting chemokine (C-X-C motif) receptor 3 in thyroid autoimmunity. Recent Pat Endocr Metab Immune Drug Discovery (2014) 8(2):95-101. doi: $10.2174 / 1872214808666140623114315$

128. Fallahi P, Ferrari SM, Elia G, Nasini F, Colaci M, Giuggioli D, et al. Novel Therapies for Thyroid Autoimmune Diseases. Expert Rev Clin Pharmacol (2016) 9(6):853-61. doi: 10.1586/17512433.2016.1157468

129. Antonelli A, Ferrari SM, Corrado A, Franceschini SS, Gelmini S, Ferrannini E, et al. Extra-ocular muscle cells from patients with Graves' ophthalmopathy secrete $\alpha$ (CXCL10) and $\beta$ (CCL2) chemokines under the influence of cytokines that are modulated by PPAR $\gamma$. Autoimmun Rev (2014) 13(11):1160-6. doi: 10.1016/j.autrev.2014.08.025

130. Pan X, Kaminga AC, Wu Wen S, Liu A. Chemokines in post-traumatic stress disorder: A network meta-analysis. Brain Behav Immun (2020). doi: 10.1016/ j.bbi.2020.11.033

131. Pan X, Kaminga AC, Wen SW, Liu A. Chemokines in hepatocellular carcinoma: a meta-analysis. Carcinogenesis (2020). doi: 10.1093/carcin/ bgaal06

132. Bhat AA, Nisar S, Maacha S, Carneiro-Lobo TC, Akhtar S, Siveen KS, et al. Cytokine-chemokine network driven metastasis in esophageal cancer; promising avenue for targeted therapy. Mol Cancer (2021) 20(1):2. doi: 10.1186/s12943-020-01294-3

133. Pan X, Chiwanda Kaminga A, Liu A, Wen SW, Chen J, Luo J. Chemokines in Non-alcoholic Fatty Liver Disease: A Systematic Review and Network Meta-Analysis. Front Immunol (2020) 11:1802. doi: 10.3389/fimmu. 2020.01802

134. Akash MS, Rehman K, Chen S. Role of inflammatory mechanisms in pathogenesis of type 2 diabetes mellitus. J Cell Biochem (2013) 114(3):52531. doi: $10.1002 /$ jcb. 24402

135. Mira E, Barber DF, Almonacid L, Zaballos A, Stein JVJJ. Statins Induce Regulatory T Cell Recruitment via a CCL1 Dependent Pathwayl. (2008) 181: (5):3524-34. doi: 10.4049/jimmunol.181.5.3524

136. Hotamisligil GS, Erbay E. Nutrient sensing and inflammation in metabolic diseases. Nat Rev Immunol (2008) 8(12):923-34. doi: 10.1038/nri2449

137. Jager J, Grémeaux T, Cormont M, Le Marchand-Brustel Y, Tanti JF. Interleukin-1beta-induced insulin resistance in adipocytes through downregulation of insulin receptor substrate-1 expression. Endocrinology 148 (1):241-51. doi: 10.1210/en.2006-0692

138. Kern PA, Ranganathan S, Li C, Wood L, J. G. Adipose tissue tumor necrosis factor and interleukin-6 expression in human obesity and insulin. J Physiol (2001). doi: 10.1152/ajpendo.2001.280.5.E745

139. Kitade H, Sawamoto K, Nagashimada M, Inoue H, Yamamoto Y, Sai Y, et al. CCR5 plays a critical role in obesity-induced adipose tissue inflammation and insulin resistance by regulating both macrophage recruitment and M1/M2 status. Diabetes (2012) 61(7):1680-90. doi: 10.2337/db11-1506

140. Szalai C, Császár A, Czinner A, Szabó T, Falus AJPR. Chemokine Receptor CCR2 and CCR5 Polymorphisms in Children with InsulinDependent Diabetes Mellitus. (1999) 46(1):82-4. doi: 10.1203/00006450199907000-00014

141. Gerhardt CC, Romero IA, Cancello R, Camoin L, Strosberg ADJM, Endocrinology C. Chemokines control fat accumulation and leptin secretion by cultured human adipocytes. (2001) 175(1-2):81-92. doi: 10.1016/S0303-7207(01)00394-X

142. Chang TT, Chen J. W. J. C. D. Emerging role of chemokine CC motif ligand 4 related mechanisms in diabetes mellitus and cardiovascular disease: friends or foes? (2016) 15(1):117. doi: 10.1186/s12933-016-0439-9

143. Barbé-Tuana FM, Klein D, Ichii H, Berman DM, Coffey L, Kenyon NS, et al. CD40-CD40 ligand interaction activates proinflammatory pathways in pancreatic islets. Diabetes (2006) 55(9):2437-45. doi: 10.2337/db05-1673

144. Omatsu T, Cepinskas G, Clarson C, Patterson EK, Alharfi IM, Summers K, et al. CXCL1/CXCL8 (GRO alpha/IL-8) in human diabetic ketoacidosis plasma facilitates leukocyte recruitment to cerebrovascular endothelium in vitro. Am J Physiol-Endocrinol Metab (2014) 306(9):E1077-84. doi: 10.1152/ ajpendo.00659.2013
145. Straczkowski M, Dzienis-Straczkowska S, Stêpieñ A, Kowalska I, Szelachowska M, Kinalska I. Plasma interleukin-8 concentrations are increased in obese subjects and related to fat mass and tumor necrosis factor-alpha system. J Clin Endocrinol Metab (2002) 87(10):4602-6. doi: $10.1210 /$ jc.2002-020135

146. Bruun JM, Lihn AS, Madan AK, Pedersen SB, Schiøtt KM, Fain JN, et al. Higher production of IL-8 in visceral vs. subcutaneous adipose tissue. Implication of nonadipose cells in adipose tissue. Am J Physiol Endocrinol Metab (2004) 286(1):E8-13. doi: 10.1152/ajpendo.00269.2003

147. Schulthess FT, Paroni F, Sauter NS, Shu L, Ribaux P, Haataja L, et al. CXCL10 Impairs $\beta$ Cell Function and Viability in Diabetes through TLR4 Signaling. Cell Metab (2009) 9(2):125-39. doi: 10.1016/j.cmet.2009.01.003

148. Tang Y, Zhou H, Chen A, Pittman RN, Field J. The Akt proto-oncogene links Ras to Pak and cell survival signals. J Biol Chem (2000) 275(13):9106-9. doi: $10.1074 / j b c .275 .13 .9106$

149. Bergmann K, Sypniewska G. Secreted frizzled-related protein 4 (SFRP4) and fractalkine (CX3CL1) - Potential new biomarkers for $\beta$-cell dysfunction and diabetes. Clin Biochem (2014) 47(7-8):529-32. doi: 10.1016/ j.clinbiochem.2014.03.007

150. Cefalu WT. Fractalkine: a cellular link between adipose tissue inflammation and vascular pathologies. Diabetes (2011) 60(5):1380-2. doi: 10.2337/db110239

151. Wan Y, Evans RM. Rosiglitazone activation of PPARgamma suppresses fractalkine signaling. J Mol Endocrinol (2010) 44(2):135-42. doi: 10.1677/ jme-09-0090

152. van Genugten RE, Utzschneider KM, Tong J, Gerchman F, Zraika S, Udayasankar J, et al. Effects of sex and hormone replacement therapy use on the prevalence of isolated impaired fasting glucose and isolated impaired glucose tolerance in subjects with a family history of type 2 diabetes. Diabetes (2006) 55(12):3529-35. doi: 10.2337/db06-0577

153. Romero-Farina G, Aguadé-Bruix S, Cuellar-Calabria H, Pizzi MN, Roque A, Candell-Riera J. Gender differences in outcome in patients with diabetes mellitus. J Nucl Cardiol (2020). doi: 10.1007/s12350-020-02195-0

154. Kautzky-Willer A, Harreiter J, Pacini G. Sex and Gender Differences in Risk, Pathophysiology and Complications of Type 2 Diabetes Mellitus. Endocr Rev (2016) 37(3):278-316. doi: 10.1210/er.2015-1137

155. Galimberti D, Scalabrini D, Fenoglio C, De Riz M, Comi C, Venturelli E, et al. Gender-specific influence of the chromosome 16 chemokine gene cluster on the susceptibility to Multiple Sclerosis. J Neurol Sci (2008) 267(1-2):86-90. doi: $10.1016 /$ j.jns.2007.10.001

156. Chen Y, Vaughan RW, Kondeatis E, Fortune F, Graham EM, Stanford MR, et al. Chemokine gene polymorphisms associate with gender in patients with uveitis. Tissue Antigens (2004) 63(1):41-5. doi: 10.1111/j.13990039.2004.00150.x

157. Nagafusa H, Sayama K. Age-related chemokine alterations affect IgA secretion and gut immunity in female mice. Biogerontology (2020). doi: 10.1007/s10522-020-09877-9

158. Engelbrecht C, Sardinha LR, Rizzo LV. Cytokine and Chemokine Concentration in the Tear of Patients with Age-Related Cataract. Curr Eye Res (2020) 1-6. doi: 10.1080/02713683.2020.1715445

159. Seidler S, Zimmermann HW, Bartneck M, Trautwein C, Tacke F. Agedependent alterations of monocyte subsets and monocyte-related chemokine pathways in healthy adults. BMC Immunol (2010) 11:30. doi: 10.1186/14712172-11-30

160. Janesch P, Stulik L, Rouha H, Varga C, Steinhäuser J, Zerbs M, et al. Agerelated changes in the levels and kinetics of pulmonary cytokine and chemokine responses to Streptococcuspneumoniae in mouse pneumonia models. Cytokine (2018) 111:389-97. doi: 10.1016/j.cyto.2018.09.012

161. Antonelli A, Rotondi M, Fallahi P, Romagnani P, Ferrari SM, Ferrannini E, et al. Age-dependent changes in CXC chemokine ligand 10 serum levels in euthyroid subjects. J Interferon Cytokine Res (2005) 25(9):547-52. doi: 10.1089/jir.2005.25.547

162. Yuan L, Liu A, Qiao L, Sheng B, Xu M, Li W, et al. The relationship of CSF and plasma cytokine levels in HIV infected patients with neurocognitive impairment. BioMed Res Int (2015) 2015:506872. doi: 10.1155/2015/506872

163. Clifford V, Tebruegge M, Zufferey C, Germano S, Forbes B, Cosentino L, et al. Cytokine biomarkers for the diagnosis of tuberculosis infection and 
disease in adults in a low prevalence setting. Tuberculosis (Edinb) (2019) 114:91-102. doi: 10.1016/j.tube.2018.08.011

Conflict of Interest: The authors declare that the research was conducted in the absence of any commercial or financial relationships that could be construed as a potential conflict of interest.
Copyright (c) 2021 Pan, Kaminga, Wen and Liu. This is an open-access article distributed under the terms of the Creative Commons Attribution License (CC BY). The use, distribution or reproduction in other forums is permitted, provided the original author(s) and the copyright owner(s) are credited and that the original publication in this journal is cited, in accordance with accepted academic practice. No use, distribution or reproduction is permitted which does not comply with these terms. 